IZA DP No. 7315

Population Average Gender Effects

Tymon Stoczyński

March 2013

Forschungsinstitut zur Zukunft der Arbeit Institute for the Study of Labor 


\title{
Population Average Gender Effects
}

\author{
Tymon Słoczyński \\ Warsaw School of Economics \\ and IZA
}
Discussion Paper No. 7315
March 2013

\author{
IZA \\ P.O. Box 7240 \\ 53072 Bonn \\ Germany \\ Phone: +49-228-3894-0 \\ Fax: +49-228-3894-180 \\ E-mail: iza@iza.org
}

Any opinions expressed here are those of the author(s) and not those of IZA. Research published in this series may include views on policy, but the institute itself takes no institutional policy positions. The IZA research network is committed to the IZA Guiding Principles of Research Integrity.

The Institute for the Study of Labor (IZA) in Bonn is a local and virtual international research center and a place of communication between science, politics and business. IZA is an independent nonprofit organization supported by Deutsche Post Foundation. The center is associated with the University of Bonn and offers a stimulating research environment through its international network, workshops and conferences, data service, project support, research visits and doctoral program. IZA engages in (i) original and internationally competitive research in all fields of labor economics, (ii) development of policy concepts, and (iii) dissemination of research results and concepts to the interested public.

IZA Discussion Papers often represent preliminary work and are circulated to encourage discussion. Citation of such a paper should account for its provisional character. A revised version may be available directly from the author. 


\section{ABSTRACT}

\section{Population Average Gender Effects ${ }^{*}$}

In this paper I develop a consistent estimator of the population average treatment effect (PATE) which is based on a nonstandard version of the Oaxaca-Blinder decomposition. As a result, I extend the recent literature which has utilized the treatment effects framework to reinterpret this technique, and propose an alternative solution to its fundamental problem of comparison group choice. I also use the Oaxaca-Blinder decomposition and its semiparametric extension to decompose gender wage differentials with the UK Labour Force Survey (LFS) data, while providing separate estimates of the average gender effect on men, women, and the whole population.

JEL Classification: $\quad \mathrm{C} 21, \mathrm{~J} 31, \mathrm{~J} 71$

Keywords: decomposition methods, gender wage gaps, treatment effects

Corresponding author:

Tymon Słoczyński

Department of Economics I

Warsaw School of Economics

ul. Madalińskiego 6/8 p. 228

02-513 Warszawa

Poland

E-mail: tymon.sloczynski@gmail.com

\footnotetext{
*I am grateful to Krzysztof Karbownik and Michał Myck for their detailed comments on previous drafts of this paper as well as to Arun Advani, Joshua Angrist, Anna Baranowska-Rataj, Thomas Crossley, Patrick Kline, Mateusz Myśliwski, Ronald Oaxaca, Adam Szulc, Glen Waddell, and seminar and conference participants in Cambridge (RES), Dublin (ISNE), Esch-sur-Alzette (CEPS/INSTEAD), Kraków, Málaga (EEA), Nuremberg (IAB), Odense, Trento (Brucchi Luchino), and Warsaw for useful comments and discussions. I also gratefully acknowledge the financial support for this research from the National Science Centre (grant DEC-2012/05/N/HS4/00395) as well as the "Weź stypendium - dla rozwoju" scholarship programme. Moreover, I would like to thank the Clifford and Mary Corbridge Trust, the Cambridge European Trust, and the Faculty of Economics at the University of Cambridge for financial support which allowed me to undertake graduate studies at the University of Cambridge where this project was started. Data used in this paper come from the UK Data Archive at the University of Essex. It bears no responsibility, however, for data analysis or interpretation presented in this paper.
} 


\section{Introduction}

Since the seminal contributions of Oaxaca (1973) and Blinder (1973), one of the most extensive strands of the literature in empirical labor economics has aimed at decomposing intergroup wage differentials into components attributable to group composition and net effects of group membership, often referred to as the explained component and the unexplained component, respectively. Recently, several researchers (Barsky et al. 2002; Black et al. 2006; Melly 2006; Fortin, Lemieux, and Firpo 2011) have noted that the unexplained component in the most basic version of the Oaxaca-Blinder decomposition is also a consistent estimator of the population average treatment effect on the treated (PATT), thus incorporating this technique into the treatment effects literature. Kline (2011) has shown that such an estimator satisfies a beneficial "double robustness" property (Robins, Rotnitzky, and Zhao 1994), since it constitutes a propensity score reweighting estimator based on a linear model for the treatment odds. At the same time, semiparametric and nonparametric extensions of the Oaxaca-Blinder decomposition have been proposed to account for possible nonlinearities in the existing wage structures (Barsky et al. 2002; Black et al. 2006; Frölich 2007; Mora 2008; Ñopo 2008) and the decomposition literature has been extended to other distributional statistics besides the mean (Juhn, Murphy, and Pierce 1993; DiNardo, Fortin, and Lemieux 1996; Machado and Mata 2005; Melly 2005; Firpo, Fortin, and Lemieux 2007; Chernozhukov, Fernández-Val, and Melly 2012).

One of the major discussions in the Oaxaca-Blinder decomposition literature has concerned the comparison group choice problem, i.e. the question of which wage structure should be used as the counterfactual for observed wages. ${ }^{1}$ Both Oaxaca (1973) and Blinder (1973), whose main goal was to study U.S. gender wage gaps, referred to the problem of choosing either male or female wage coefficients as an "index number problem", thus suggesting this choice to be unclear. ${ }^{2}$ Subsequent contributions have established a ten-

\footnotetext{
${ }^{1}$ Fortin et al. (2011) have referred to this as the "reference group choice problem". I prefer the expression of "comparison group" to distinguish this issue from the omitted group problem which is also sometimes referred to as the issue of choosing "reference groups" (see, e.g., Oaxaca and Ransom 1999).

${ }^{2}$ As Oaxaca (1973, p. 695) put it: "On the basis of either of two assumptions, we can estimate the male-female wage ratio that would exist in the absence of discrimination: If there were no discrimination, 1) the wage structure currently faced by females would also apply to males; or 2) the wage structure currently faced by males would also apply to females".
} 
dency to regard the comparison coefficients as the "nondiscriminatory" or "competitive" wage structure (Reimers 1983; Cotton 1988; Neumark 1988; Oaxaca and Ransom 1994; Fortin 2008). It is only recently that Fortin et al. (2011) have distinguished between comparison wage structures based on the assumption of "simple counterfactual treatment" (Oaxaca 1973; Blinder 1973) and alternative structures which "represent the appropriate counterfactual for the way women would be paid in the absence of labor market discrimination" (Fortin et al. 2011, p. 47). In that case, the latter structures are assumed to capture what would happen in general equilibrium if discrimination ceased to exist. ${ }^{3}$

In this paper I challenge this common practice of interpreting the propositions of Reimers (1983), Cotton (1988), and Fortin (2008) as reflecting "the world without discrimination". First, neither of these propositions has been based on a theoretical model of the labor market, so they can hardly address such general equilibrium considerations. Second, I use the treatment effects framework to show that these decompositions are easily interpretable within it, and they estimate some generally uninteresting weighted averages of subpopulation-specific average treatment effects.

A natural question in this context is whether the population average treatment effect (PATE) can be consistently estimated with some new version of the Oaxaca-Blinder decomposition. I derive such a new estimator which uses a linear combination of the regression coefficients for both subpopulations (treated and nontreated, men and women, union and nonunion workers, etc.) as the comparison wage structure. However, these coefficients are weighted in a nonstandard way, namely the sample proportion of group one is used to weight the coefficients for group two, and vice versa. Although such a weighting procedure may at first look counterintuitive, ${ }^{4}$ the treatment effects framework provides a clear rationale for this approach. Precisely, the role of each group's wage structure is to serve as counterfactual for the other group, so we need more weight to be

\footnotetext{
${ }^{3}$ This distinction mirrors the well-known discussion of union/nonunion wage gaps and wage gains in Lewis (1986).

${ }^{4}$ Note that a similar estimator had already been used by Duncan and Leigh (1985) to estimate union wage premiums, but such an approach was heavily criticized - as "not a very intuitive procedure" - by Oaxaca and Ransom (1988, p. 143). Neither of these papers made any reference to the treatment effects framework, which was then practically unknown in economics, while showing that such an estimator is consistent for the PATE is a major contribution of the present paper.
} 
put on the coefficients for the smaller group in order to consistently estimate the PATE.

In this paper I also provide an empirical example which uses this new estimator as well as other versions of the Oaxaca-Blinder decomposition to study gender wage differentials with the UK Labour Force Survey (LFS) data, for each year from 2002 to 2010. I also use normalized reweighting and a combination of stratification and different versions of the Oaxaca-Blinder decomposition to account for possible nonlinearities in the existing wage structures, and provide separate estimates of three parameters which I refer to as the population average gender effect (PAGE), the population average gender effect on men (PAGM), and the population average gender effect on women (PAGW). This is the first paper to clarify the distinction between these parameters and provide separate estimates for each of them. ${ }^{5}$

The remainder of this paper is organized as follows. In the next section, I briefly review the treatment effects framework and the Oaxaca-Blinder decomposition. In Section 3, I provide my theoretical contributions. In Section 4, I describe an empirical application to UK gender wage differentials. Finally, I conclude and review my findings in Section 5.

\section{Background}

\subsection{The Treatment Effects Framework}

Consider a population of $N$ individuals $(i=1, \ldots, N)$ who belong to either of two mutually exclusive groups indexed by $d_{i} \in\{0,1\}{ }^{6}$ The division of individuals into these two groups is based on whether an individual has been exposed to regime referred to as

\footnotetext{
${ }^{5}$ Note, however, that I do not put forward a causal interpretation of these results, and do not use the concept of potential outcomes to define average gender effects. First, no manipulation of the "treatment" status is (typically) available in the context of being male or female. Hence no well-defined potential outcomes exist. Second, the assumption of unconfoundedness is implausible in a study of gender wage differentials, because in most studies there are several omitted control variables which have been shown to be correlated with both gender and wages. Such covariates (which are absent in the majority of microeconomic datasets) include subject of degree (Brown and Corcoran 1997; Loury 1997; Machin and Puhani 2003; Black et al. 2008), test scores (Blackburn 2004), absenteeism (Ichino and Moretti 2009), gender role attitudes (Fortin 2005), propensity to negotiate wages (Leibbrandt and List 2012), and various personality traits (Mueller and Plug 2006; Fortin 2008; Manning and Swaffield 2008). For an insightful discussion of "causal effects of perceived immutable characteristics", see also Greiner and Rubin (2011).

${ }^{6}$ Since the treatment effects framework is now widespread in empirical microeconomics, I assume the reader to be reasonably familiar with its basics. Recent reviews are given in Angrist and Pischke (2009), Blundell and Costa Dias (2009), and Imbens and Wooldridge (2009).
} 
treatment. If unit $i$ has been (has not been) exposed to treatment, she is called a treated (nontreated) individual and $d_{i}=1\left(d_{i}=0\right)$. Moreover, $\sum_{i=1}^{N} d_{i}=N_{1}$ and $N_{0}+N_{1}=N$, i.e. there are $N_{1}\left(N_{0}\right)$ treated (nontreated) individuals in the population. For each $i$, a row vector of covariates, $X_{i}$, is also observed.

Let there also be a variable, the outcome, whose codetermination by the treatment is of key interest. For each individual $i$, the realized (observable) outcome is denoted by $y_{i}$. It is assumed, however, there exist two potential outcomes which could have been observed, $y_{0 i}$ and $y_{1 i}$, dependent on whether the individual has been exposed to treatment. If $d_{i}=1$, then it is only $y_{1 i}$, the treated outcome, which is realized (and observed). On the other hand, if $d_{i}=0$, then we only observe $y_{0 i}$, the nontreated outcome. Consequently, it is the group membership of each individual $i$ which causes one of the potential outcomes to become observable and the other to become counterfactual.

An extensive literature seeks to identify and estimate treatment effects. An individualspecific treatment effect is defined as $\tau_{i}=y_{1 i}-y_{0 i}$. Typically, these effects are averaged over certain (sub)populations of interest. For the whole population, the population average treatment effect (PATE) is the appropriate parameter:

$$
\tau_{P A T E}=\mathrm{E}\left[\tau_{i}\right]=\mathrm{E}\left[y_{1 i}-y_{0 i}\right]
$$

Alternatively, individual-specific treatment effects can be averaged over the subpopulation of treated (nontreated) individuals to obtain the PATT (PATN), i.e. the population average treatment effect on the treated (nontreated):

$$
\tau_{P A T T}=\mathrm{E}\left[\tau_{i} \mid d_{i}=1\right] \quad \text { and } \quad \tau_{P A T N}=\mathrm{E}\left[\tau_{i} \mid d_{i}=0\right]
$$

There are two main strands in the treatment effects literature, typically referred to as selection on observables and selection on unobservables, and this division is based on their identifying assumptions. The present paper refers only to selection on observables (unconfoundedness), i.e. a strand which assumes that treatment is orthogonal to potential outcomes, conditional on $X_{i}$. Under unconfoundedness various average treatment effects 
of interest can be estimated using regression methods, methods based on the propensity score, matching on covariates, and their various combinations (see, e.g., Imbens and Wooldridge 2009 for an excellent review). Recent contributions of Barsky et al. (2002), Black et al. (2006), Melly (2006), Fortin et al. (2011), and Kline (2011) have noted that a consistent estimator of the PATT is also provided by the Oaxaca-Blinder decomposition.

\subsection{The Oaxaca-Blinder Decomposition}

Let the model for outcomes be linear and separable in observable and unobservable characteristics, and allow the regression coefficients to be different for both groups of interest:

$$
y_{i}=X_{i} \beta_{1}+v_{1 i} \quad \text { if } \quad d_{i}=1 \quad \text { and } \quad y_{i}=X_{i} \beta_{0}+v_{0 i} \quad \text { if } \quad d_{i}=0,
$$

where $\mathrm{E}\left[v_{1 i} \mid X_{i}\right]=\mathrm{E}\left[v_{0 i} \mid X_{i}\right]=0$. Suppose we are concerned with decomposing gender wage differentials. In that case, let $d_{i}=1$ for males and $d_{i}=0$ for females, and let $y_{i}$ be the observed (log) wages. The gender wage differential, $\mathrm{E}\left[y_{i} \mid d_{i}=1\right]-\mathrm{E}\left[y_{i} \mid d_{i}=0\right]$, can then be decomposed into two components:

$$
\begin{aligned}
\mathrm{E}\left[y_{i} \mid d_{i}=1\right]-\mathrm{E}\left[y_{i} \mid d_{i}=0\right]= & \mathrm{E}\left[X_{i} \mid d_{i}=1\right] \cdot\left(\beta_{1}-\beta_{0}\right) \\
& +\left(\mathrm{E}\left[X_{i} \mid d_{i}=1\right]-\mathrm{E}\left[X_{i} \mid d_{i}=0\right]\right) \cdot \beta_{0},
\end{aligned}
$$

where the first element, $\mathrm{E}\left[X_{i} \mid d_{i}=1\right] \cdot\left(\beta_{1}-\beta_{0}\right)$, reflects gender differences in regression coefficients, and is often referred to as the unexplained component, while the second element, $\left(\mathrm{E}\left[X_{i} \mid d_{i}=1\right]-\mathrm{E}\left[X_{i} \mid d_{i}=0\right]\right) \cdot \beta_{0}$, reflects gender differences in mean covariate values, and is often referred to as the explained component. Similarly:

$$
\begin{aligned}
\mathrm{E}\left[y_{i} \mid d_{i}=1\right]-\mathrm{E}\left[y_{i} \mid d_{i}=0\right]= & \mathrm{E}\left[X_{i} \mid d_{i}=0\right] \cdot\left(\beta_{1}-\beta_{0}\right) \\
& +\left(\mathrm{E}\left[X_{i} \mid d_{i}=1\right]-\mathrm{E}\left[X_{i} \mid d_{i}=0\right]\right) \cdot \beta_{1} .
\end{aligned}
$$

The difference between Equations 4 and 5 rests upon using alternate comparison coefficients to calculate the explained component as well as measuring the distance between 
the regression functions, $\beta_{1}-\beta_{0}$, for a different set of covariate values. Moreover, under unconfoundedness consistent estimators of the PATT and the PATN are also provided by Equations 4 and 5:

$$
\tau_{P A T T}=\mathrm{E}\left[X_{i} \mid d_{i}=1\right] \cdot\left(\beta_{1}-\beta_{0}\right) \quad \text { and } \quad \tau_{P A T N}=\mathrm{E}\left[X_{i} \mid d_{i}=0\right] \cdot\left(\beta_{1}-\beta_{0}\right) .
$$

There has been a long-lasting tendency in the decomposition literature to claim that the choice of the comparison group in this context (choosing between Equations 4 and 5) is necessarily ambiguous (see, e.g., Oaxaca 1973; Elder, Goddeeris, and Haider 2010). ${ }^{7}$ The standard response has been to suggest alternative wage structures to solve this comparison group choice problem. Such an approach has often been referred to as "generalized Oaxaca-Blinder", and it involves performing an alternative decomposition:

$$
\begin{aligned}
\mathrm{E}\left[y_{i} \mid d_{i}=1\right]-\mathrm{E}\left[y_{i} \mid d_{i}=0\right]= & \mathrm{E}\left[X_{i} \mid d_{i}=1\right] \cdot\left(\beta_{1}-\beta^{*}\right)+\mathrm{E}\left[X_{i} \mid d_{i}=0\right] \cdot\left(\beta^{*}-\beta_{0}\right) \\
& +\left(\mathrm{E}\left[X_{i} \mid d_{i}=1\right]-\mathrm{E}\left[X_{i} \mid d_{i}=0\right]\right) \cdot \beta^{*},
\end{aligned}
$$

where $\beta^{*}$ is the set of comparison coefficients, typically referred to as the "nondiscriminatory" or "competitive" wage structure.

Several influential papers have been devoted to suggesting alternative sets of comparison coefficients for Equation 7, and these coefficients have often been formulated as $\beta^{*}=\lambda \cdot \beta_{1}+(1-\lambda) \cdot \beta_{0}$ where $\lambda \in\{0,1\}$ is a weighting factor. If $\lambda=0$, then women are used as reference, $\beta^{*}=\beta_{0}$, and Equation 7 simplifies to Equation 4. Similarly, if $\lambda=1$, then men are used as reference, $\beta^{*}=\beta_{1}$, and Equation 7 simplifies to Equation 5 . Alternatively, Reimers (1983) suggested $\lambda=\frac{1}{2}$ and Cotton (1988) suggested $\lambda=\frac{N_{1}}{N_{0}+N_{1}}$, the population proportion of group one. Moreover, Neumark (1988) developed a simple model of Beckerian discrimination, and showed that identification of the nondiscriminatory wage structure is ensured, for example, if the utility function of the representative producer is homogeneous of degree zero with respect to male and female labor inputs (within each type of labor). Such a wage structure can be approximated by regression

\footnotetext{
${ }^{7}$ See, e.g., Black et al. $(2006,2008)$ for a different view which is close in spirit to the present paper.
} 
coefficients in a pooled model which excludes group membership (Neumark 1988). Although this solution to the comparison group choice problem was popularized by Oaxaca and Ransom (1994) and has been the most popular alternative to the basic OaxacaBlinder decomposition (Weichselbaumer and Winter-Ebmer 2005), it has been criticized by Fortin (2008) and Elder et al. (2010), since exclusion of the group membership dummy can bias coefficients on other covariates which also affects the unexplained component. Therefore, Fortin (2008) has proposed to use a pooled model including group membership as the comparison wage structure. As noted by Fortin (2008) and Fortin et al. (2011), the unexplained component in such a decomposition is equal (by construction) to the coefficient on the group membership dummy in linear regression. Consequently, empirical researchers can currently choose between six versions of the Oaxaca-Blinder decomposition. ${ }^{8}$ Below I provide a further alternative and a treatment-effects reinterpretation of Reimers (1983), Cotton (1988), and Fortin (2008).

\section{Population Average Gender Effects}

\subsection{New Estimands}

Using notation from Section 2 , let $d_{i}=1$ for males and $d_{i}=0$ for females. Also, let $y_{i}$ be the observed ( $\log$ ) wage. In that case, $\mathrm{E}\left[y_{i} \mid X_{i}=x, d_{i}=1\right]$ is the expected (log) wage of a male with observable characteristics $X_{i}=x$ and $\mathrm{E}\left[y_{i} \mid X_{i}=x, d_{i}=0\right]$ is the expected $(\log )$ wage of a female with these characteristics. Moreover, define the average gender effect conditional on $X_{i}=x$ as $\tau(x)=\mathrm{E}\left[y_{i} \mid X_{i}=x, d_{i}=1\right]-\mathrm{E}\left[y_{i} \mid X_{i}=x, d_{i}=0\right]$, i.e. the gap between the expected $(\log )$ wages of a male and a female with $X_{i}=x .^{9}$ Dependent on the question we wish to answer, we may average these conditional average gender effects over the whole population, over the subpopulation of men or over the

\footnotetext{
${ }^{8}$ These include: two original versions of the Oaxaca-Blinder decomposition which also provide consistent estimators of the PATT and the PATN (Oaxaca 1973; Blinder 1973); and four further "generalized Oaxaca-Blinder" decompositions (Reimers 1983; Cotton 1988; Neumark 1988; Fortin 2008).

${ }^{9}$ Note, again, that the notion of potential outcomes is not used in this definition. Also, unconfoundedness is not required to identify such gaps, as long as they are not interpreted as causal. For a related discussion of the causal interpretability of counterfactual distributions, see Chernozhukov et al. (2012).
} 
subpopulation of women. Define:

$$
\tau_{P A G E}=\mathrm{E}\left[\tau\left(X_{i}\right)\right]
$$

as the population average gender effect (PAGE). Note that this parameter is an equivalent of the population average treatment effect (PATE). Moreover, denote:

$$
\tau_{P A G M}=\mathrm{E}\left[\tau\left(X_{i}\right) \mid d_{i}=1\right] \quad \text { and } \quad \tau_{P A G W}=\mathrm{E}\left[\tau\left(X_{i}\right) \mid d_{i}=0\right]
$$

as the population average gender effect on men (PAGM) and the population average gender effect on women (PAGW), respectively. Similarly, these parameters can be regarded as equivalents of the PATT and the PATN. Moreover, since $d_{i}=1$ for males, the PAGM can be consistently estimated with the unexplained component of the Oaxaca-Blinder decomposition in Equation 4, while the PAGW can be consistently estimated with the unexplained component of the decomposition in Equation 5. ${ }^{10}$ Consequently, as already noted by Black et al. (2006, 2008), there can hardly be any ambiguity about choosing either male or female wage structure in the Oaxaca-Blinder decomposition, in spite of many views to the contrary (see, e.g., Elder et al. 2010, p. 284). Any such choice should be based on whether we are interested in the average male gain in comparison with similar women (PAGM) or in the average female loss in comparison with similar men (PAGW). No assumptions about (and no reference to) the "nondiscriminatory" wage structure are needed to perform a meaningful decomposition, in spite of a strong tendency in the literature to claim otherwise (see, e.g., Oaxaca and Ransom 1994, p. 8; Mora 2008, p. 464).

\subsection{Advantages of the PAGE Approach}

In this paper I suggest a considerable reformulation of the Oaxaca-Blinder decomposition methodology. Instead of comparing current wages of both genders with an assumed

\footnotetext{
${ }^{10}$ In other words, whenever we use the male wage structure as reference in the Oaxaca-Blinder decomposition, the unexplained component provides an estimate of the population average gender effect on women $(\mathrm{PAGW})$. If we use the female wage structure as reference, we estimate the population average gender effect on men (PAGM).
} 
"nondiscriminatory" wage structure, I argue that it is more informative to compare current wages of men with current wages of similar women (and vice versa) and to estimate the corresponding population average gender effects. This subsection lays out several arguments for such an approach.

First, as already noted, comparisons of individual wages with an hypothesized nondiscriminatory wage structure are unlikely to be meaningful if such a structure is not derived from a theoretical model of the labor market. In the absence of such a model, a decomposition intends to be structural without a structure, and this is true in the case of the propositions in Reimers (1983), Cotton (1988), and Fortin (2008). The only exception is the Neumark (1988) decomposition which is derived from a theoretical model of discrimination whose assumptions are, however, highly debatable. ${ }^{11}$

Second, the idea of comparing current wages of men (women) with current wages of women (men) who possess similar observable characteristics is arguably more intuitive and closer to the most common view of nondiscrimination as "equal pay for equal work".

Third, an explicit definition of the underlying parameters as population average gender effects induces a good explanation of an important empirical regularity which has often been quoted in the decomposition literature. Namely, Fortin et al. (2011, p. 47) have acknowledged that "[t]ypically ..., with the female wage structure as reference, the explained part of the decomposition (composition effect) is smaller than with the male wage structure as reference". Note that the traditional approach to the Oaxaca-Blinder decomposition does not allow for a straightforward interpretation of such a phenomenon, and indeed Fortin et al. (2011) do not provide it. However, as soon as one realizes that this empirical regularity is equivalent to the PAGM being consistently larger than the PAGW, an interpretation immediately becomes clear. Precisely, because men are located, on average, higher in the wage distribution than women, such a phenomenon means that

\footnotetext{
${ }^{11}$ Namely, Neumark (1988) based his decomposition on a model of Beckerian discrimination. However, statistical discrimination was therefore assumed out, while such a restriction is not necessarily supported by empirical studies. Neumark (1999) and Belley, Havet, and Lacroix (2012) have suggested that statistical discrimination against women exists in the U.S. labor market. In nonlabor settings, Ayres and Siegelman (1995) and List (2004) discovered statistical discrimination against women in the car market and in the sportscard market, respectively. On the other hand, Levitt (2004) and Antonovics, Arcidiacono, and Walsh (2005) ruled out statistical discrimination in a TV game show. See Oettinger (1996), Altonji and Pierret (2001), and Siniver (2011) for studies of other groups of workers.
} 
average gender effects tend to increase with wages. In such a situation, one can suspect, for example, the existence of a glass ceiling (see, e.g., Albrecht, Björklund, and Vroman 2003; Arulampalam, Booth, and Bryan 2007; de la Rica, Dolado, and Llorens 2008), i.e. a situation in which the wage gap "increases throughout the wage distribution with a sharp acceleration in the upper tail of the distribution" (Albrecht et al. 2003).

Fourth, as noted by Fortin et al. (2011), such a relationship between the OaxacaBlinder decomposition literature and the treatment effects literature allows for clarifying the assumptions which underlie decomposition methods as well as using selected estimators of average treatment effects in studies of gender wage differentials. If an estimator has good properties in estimating the PATE (PATT), it is also advisable for the PAGE (PAGM, PAGW). To give an example, in Section 4 I use normalized reweighting and a combination of stratification and different versions of the Oaxaca-Blinder decomposition to provide estimates of the PAGE, the PAGM, and the PAGW in the UK labor market.

\subsection{A Consistent Estimator of the PAGE/PATE}

In this subsection I develop a consistent estimator of the population average gender effect (PAGE) and, equivalently, of the population average treatment effect (PATE). This alternative estimator is based on a nonstandard version of the Oaxaca-Blinder decomposition, and it uses Equation 7 and a comparison wage structure constructed as a specific linear combination of the regression coefficients for both subpopulations of interest.

Proposition 1 (Oaxaca-Blinder as an Estimator of the PAGE/PATE). The population average gender effect (PAGE) can be consistently estimated with Equation 7 if $\beta^{*}=\frac{N_{0}}{N_{0}+N_{1}} \cdot \beta_{1}+\frac{N_{1}}{N_{0}+N_{1}} \cdot \beta_{0}$.

Proof. Combine Equation 7 with $\beta^{*}=\frac{N_{0}}{N_{0}+N_{1}} \cdot \beta_{1}+\frac{N_{1}}{N_{0}+N_{1}} \cdot \beta_{0}$ and reformulate:

$$
\begin{aligned}
\mathrm{E}\left[y_{i} \mid d_{i}=1\right]-\mathrm{E}\left[y_{i} \mid d_{i}=0\right]= & \mathrm{E}\left[X_{i} \mid d_{i}=1\right] \cdot\left(\beta_{1}-\beta^{*}\right)+\mathrm{E}\left[X_{i} \mid d_{i}=0\right] \cdot\left(\beta^{*}-\beta_{0}\right) \\
& +\left(\mathrm{E}\left[X_{i} \mid d_{i}=1\right]-\mathrm{E}\left[X_{i} \mid d_{i}=0\right]\right) \cdot \beta^{*} \\
= & \mathrm{E}\left[X_{i} \mid d_{i}=1\right] \cdot\left(\beta_{1}-\left(\frac{N_{0}}{N_{0}+N_{1}} \cdot \beta_{1}+\frac{N_{1}}{N_{0}+N_{1}} \cdot \beta_{0}\right)\right)
\end{aligned}
$$




$$
\begin{aligned}
& +\mathrm{E}\left[X_{i} \mid d_{i}=0\right] \cdot\left(\left(\frac{N_{0}}{N_{0}+N_{1}} \cdot \beta_{1}+\frac{N_{1}}{N_{0}+N_{1}} \cdot \beta_{0}\right)-\beta_{0}\right) \\
& +\left(\mathrm{E}\left[X_{i} \mid d_{i}=1\right]-\mathrm{E}\left[X_{i} \mid d_{i}=0\right]\right) \cdot \beta^{*} \\
= & \frac{N_{1}}{N_{0}+N_{1}} \cdot \mathrm{E}\left[X_{i} \mid d_{i}=1\right] \cdot\left(\beta_{1}-\beta_{0}\right) \\
& +\frac{N_{0}}{N_{0}+N_{1}} \cdot \mathrm{E}\left[X_{i} \mid d_{i}=0\right] \cdot\left(\beta_{1}-\beta_{0}\right) \\
& +\left(\mathrm{E}\left[X_{i} \mid d_{i}=1\right]-\mathrm{E}\left[X_{i} \mid d_{i}=0\right]\right) \cdot \beta^{*} \\
= & \frac{N_{1}}{N_{0}+N_{1}} \cdot \tau_{P A G M}+\frac{N_{0}}{N_{0}+N_{1}} \cdot \tau_{P A G W} \\
& +\left(\mathrm{E}\left[X_{i} \mid d_{i}=1\right]-\mathrm{E}\left[X_{i} \mid d_{i}=0\right]\right) \cdot \beta^{*} \\
= & \tau_{P A G E}+\left(\mathrm{E}\left[X_{i} \mid d_{i}=1\right]-\mathrm{E}\left[X_{i} \mid d_{i}=0\right]\right) \cdot \beta^{*}
\end{aligned}
$$

Q.E.D.

Although using the population proportion of group one (two) to weight the coefficients for group two (one) may at first look counterintuitive, each of the wage structures plays a clearly defined role in such a decomposition - to serve as counterfactual for the other group. This is exactly the reason why more weight should be put on the wage structure of the smaller group which is used to provide a counterfactual for the larger one.

Interestingly, this alternative estimator is equivalent to a flexible OLS estimator of the PATE presented in Wooldridge (2002) and Imbens and Wooldridge (2009), i.e. $\tau_{P A T E}$ can equivalently be estimated as the coefficient on $d_{i}$ in the regression of $y_{i}$ on $1, d_{i}, X_{i}$, and $d_{i} \cdot\left(X_{i}-\bar{X}\right)$. Precisely, Imbens and Wooldridge (2009, p. 29) show that such a flexible OLS estimator can alternatively be written as:

$$
\hat{\tau}_{P A T E}=\bar{y}_{1}-\bar{y}_{0}-\left(\frac{N_{0}}{N_{0}+N_{1}} \cdot \hat{\beta}_{1}+\frac{N_{1}}{N_{0}+N_{1}} \cdot \hat{\beta}_{0}\right) \cdot\left(\bar{X}_{1}-\bar{X}_{0}\right),
$$

which is the sample counterpart of the Oaxaca-Blinder estimator in Proposition $1 .^{12}$

\footnotetext{
${ }^{12}$ Similarly, the unexplained component of the Oaxaca-Blinder decomposition in Equation 4 is equal (by construction) to the coefficient on $d_{i}$ in the regression of $y_{i}$ on $1, d_{i}, X_{i}$, and $d_{i} \cdot\left(X_{i}-\bar{X}_{1}\right)$ and the unexplained component of the Oaxaca-Blinder decomposition in Equation 5 is equal (by construction) to the coefficient on $d_{i}$ in the regression of $y_{i}$ on $1, d_{i}, X_{i}$, and $d_{i} \cdot\left(X_{i}-\bar{X}_{0}\right)$.
} 


\subsection{Reimers (1983), Cotton (1988), Fortin (2008), and PAGE}

The logic and approach of the previous subsection applies also to the well-known solutions to the comparison group choice problem which have been provided by Reimers (1983), Cotton (1988), and Fortin (2008). To preview my conclusions, each of the unexplained components in these decompositions is a consistent estimator of a weighted average of the population average gender effect on men (PAGM) and the population average gender effect on women (PAGW).

Proposition 2 (A Reinterpretation of Reimers 1983). The unexplained component of the Reimers (1983) decomposition is a consistent estimator of $\frac{1}{2} \cdot \tau_{P A G M}+\frac{1}{2} \cdot \tau_{P A G W}$, i.e. the arithmetic mean of the population average gender effect on men (PAGM) and the population average gender effect on women (PAGW).

Proof. To prove Proposition 2, combine Equation 7 with $\beta^{*}=\frac{1}{2} \cdot \beta_{1}+\frac{1}{2} \cdot \beta_{0}$ and reformulate:

$$
\begin{aligned}
\mathrm{E}\left[y_{i} \mid d_{i}=1\right]-\mathrm{E}\left[y_{i} \mid d_{i}=0\right]= & \mathrm{E}\left[X_{i} \mid d_{i}=1\right] \cdot\left(\beta_{1}-\beta^{*}\right)+\mathrm{E}\left[X_{i} \mid d_{i}=0\right] \cdot\left(\beta^{*}-\beta_{0}\right) \\
& +\left(\mathrm{E}\left[X_{i} \mid d_{i}=1\right]-\mathrm{E}\left[X_{i} \mid d_{i}=0\right]\right) \cdot \beta^{*} \\
= & \mathrm{E}\left[X_{i} \mid d_{i}=1\right] \cdot\left(\beta_{1}-\left(\frac{1}{2} \cdot \beta_{1}+\frac{1}{2} \cdot \beta_{0}\right)\right) \\
& +\mathrm{E}\left[X_{i} \mid d_{i}=0\right] \cdot\left(\left(\frac{1}{2} \cdot \beta_{1}+\frac{1}{2} \cdot \beta_{0}\right)-\beta_{0}\right) \\
& +\left(\mathrm{E}\left[X_{i} \mid d_{i}=1\right]-\mathrm{E}\left[X_{i} \mid d_{i}=0\right]\right) \cdot \beta^{*} \\
= & \frac{1}{2} \cdot \mathrm{E}\left[X_{i} \mid d_{i}=1\right] \cdot\left(\beta_{1}-\beta_{0}\right) \\
& +\frac{1}{2} \cdot \mathrm{E}\left[X_{i} \mid d_{i}=0\right] \cdot\left(\beta_{1}-\beta_{0}\right) \\
& +\left(\mathrm{E}\left[X_{i} \mid d_{i}=1\right]-\mathrm{E}\left[X_{i} \mid d_{i}=0\right]\right) \cdot \beta^{*} \\
= & \frac{1}{2} \cdot \tau_{P A G M}+\frac{1}{2} \cdot \tau_{P A G W} \\
& +\left(\mathrm{E}\left[X_{i} \mid d_{i}=1\right]-\mathrm{E}\left[X_{i} \mid d_{i}=0\right]\right) \cdot \beta^{*} .
\end{aligned}
$$

Q.E.D. 
Consequently, the Reimers (1983) decomposition has a clear interpretation as an estimator of the arithmetic mean of the population average gender effect on men (PAGM) and the population average gender effect on women (PAGW). As an example, assume that $\tau_{P A G M}=0.3$ and $\tau_{P A G W}=0.1$, and also the proportion of men in the working population equals $60 \%$. In that case, although $\tau_{P A G E}$ would equal 0.22 , the expectation of the unexplained component of the Reimers (1983) decomposition would equal 0.2. When the proportion of men (women) in the sample changes, then the unexplained component of the Reimers (1983) decomposition does not change, even though $\tau_{P A G E}$ might increase or decrease. Anyway, the Reimers (1983) decomposition is likely to overstate the importance of the smaller group when estimating average gender effects by attaching too large a weight $\left(\frac{1}{2}>\frac{N_{0}}{N_{0}+N_{1}}\right)$ to the effect on this group.

Proposition 3 (A Reinterpretation of Cotton 1988). The unexplained component of the Cotton (1988) decomposition is a consistent estimator of $\frac{N_{0}}{N_{0}+N_{1}} \cdot \tau_{P A G M}+\frac{N_{1}}{N_{0}+N_{1}}$. $\tau_{P A G W}$, i.e. a weighted average of the population average gender effect on men (PAGM) and the population average gender effect on women (PAGW), with reversed weights attached to both these effects (the population proportion of men is used to weight the PAGW and the population proportion of women is used to weight the PAGM).

Proof. See Słoczyński (2012) for a proof of an equivalent proposition in the treatment effects context. This proof is restated in the Appendix for completeness.

Although the comparison wage structure proposed by Cotton (1988) is somehow similar to the new structure in Proposition 1, the Cotton (1988) decomposition should arguably be of little interest for empirical researchers, since it implicitly changes the "natural" weights attached to the average effects on both subpopulations of interest. Using the example above, if $\tau_{P A G M}=0.3, \tau_{P A G W}=0.1$, and $\frac{N_{1}}{N_{0}+N_{1}}=60 \%$ (and, therefore, $\tau_{P A G E}=0.22$ ), then the expectation of the unexplained component of the Cotton (1988) decomposition would equal 0.18, again overstating the importance of the smaller group. Also, note that the larger the population proportion of a given group, the more distant is the un- 
explained component of the Cotton (1988) decomposition from the average effect on this group. When the proportion of women in the working population goes up, the Cotton (1988) decomposition increases the weight which is attached to the population average gender effect on men.

Proposition 4 (A Reinterpretation of Fortin 2008 Under Homogeneous Average Gender Effects). If average gender effects are homogeneous, $\tau(x)=\tau$, the unexplained component of the Fortin (2008) decomposition is a consistent estimator of the population average gender effect (PAGE), the population average gender effect on men (PAGM), and the population average gender effect on women (PAGW).

Proof. See Wooldridge (2002, p. 611-612) for a proof of an equivalent proposition that simple OLS provides a consistent estimator of the PATE and the PATT under homogeneous treatment effects. This proof is restated in the Appendix for completeness.

If gender effects are homogeneous, i.e. $\tau(x)=\tau$ for all $x$, the Fortin (2008) decomposition provides a consistent estimator of the PAGE, the PAGM, and the PAGW. ${ }^{13}$ This result should not be surprising, as it is a simple extrapolation of the well-known proposition that simple OLS provides a consistent estimator of various average treatment effects whenever they are homogeneous. On the other hand, it is much less established what exactly is provided by simple OLS if the assumption of homogeneous treatment effects is relaxed and heterogeneity is allowed.

Proposition 5 (A Reinterpretation of Fortin 2008 Under Heterogeneous Average Gender Effects). If $X_{i}$ is a scalar whose variance is equal in the male and female subpopulations, the unexplained component of the Fortin (2008) decomposition is a consistent estimator of $\frac{N_{0}}{N_{0}+N_{1}} \cdot \tau_{P A G M}+\frac{N_{1}}{N_{0}+N_{1}} \cdot \tau_{P A G W}$, i.e. a weighted average of the population average gender effect on men (PAGM) and the population average gender effect

\footnotetext{
${ }^{13}$ The subsequent discussion uses the fact that the unexplained component of such a decomposition is equal (by construction) to the coefficient on the group membership dummy in a pooled regression (Fortin 2008; Fortin et al. 2011).
} 
on women (PAGW), with reversed weights attached to both these effects (the population proportion of men is used to weight the PAGW and the population proportion of women is used to weight the PAGM).

Proof. See Słoczyński (2012) for a proof of an equivalent proposition in the context of linear least squares regression and treatment effects. Alternatively, see Elder et al. (2010) and combine their result with Proposition 3 in the present paper. The proof is restated in the Appendix for completeness.

In a recent paper, Elder et al. (2010) discussed various versions of the Oaxaca-Blinder decomposition. For example, they proved that the coefficient on the group membership dummy in a simple linear regression is equal (by construction) to the unexplained component of the Cotton (1988) decomposition whenever $X_{i}$ is a scalar whose variance is equal in both subpopulations of interest. This result in Elder et al. (2010) is sufficient to prove Proposition 5. Precisely, if the assumption of homogeneous gender effects is relaxed, then - under these additional assumptions on $X_{i}$ - the unexplained component of the Fortin (2008) decomposition equalizes with the unexplained component of the Cotton (1988) decomposition, while this parameter - under Proposition 3 - is precisely a weighted average of the population average gender effect on men (PAGM) and the population average gender effect on women (PAGW), with reversed weights attached to both these effects. In consequence, also the Fortin (2008) decomposition might overstate the importance of the smaller group when estimating average gender effects.

Using the same numerical example again, if $\tau_{P A G M}=0.3, \tau_{P A G W}=0.1$, and $\frac{N_{1}}{N_{0}+N_{1}}=$ $60 \%\left(\tau_{P A G E}=0.22\right)$, then the expectation of the unexplained component of the Fortin (2008) decomposition would equal 0.18 whenever the assumptions above are satisfied. Clearly, these assumptions are often too strong, but Proposition 5 should still (arguably) provide a useful benchmark for predicting the behavior of the Fortin (2008) estimator.

In consequence, whenever we are concerned with gender effect heterogeneity, there is good reason to choose the new version of the Oaxaca-Blinder decomposition in Proposition 1 to estimate the population average gender effect (PAGE). When instead we use 
the Reimers (1983), Cotton (1988), or Fortin (2008) decompositions, we risk overstating the importance of the smaller subpopulation. As an extreme example, assume that the proportion of men in the population goes to zero. In that case, in the limit, the unexplained components of the Cotton (1988) and Fortin (2008) decompositions equalize with the population average gender effect on men (PAGM), i.e. the group which has become absent by assumption.

\subsection{A Semiparametric Extension}

If we indeed decide to aim at estimating the population average gender effect (PAGE), the population average gender effect on men (PAGM), and the population average gender effect on women (PAGW), i.e. parameters which are equivalent to various average treatment effects, then any of the standard estimators of the PATE and the PATT can be used to estimate the PAGE and the PAGM/PAGW, respectively, and we can safely assume that the better an estimator is for various average treatment effects, the better it is also for various average gender effects.

For example, consider a recent survey by Imbens and Wooldridge (2009) which has provided a strong case for various combinations of linear regression and either matching or methods based on the propensity score. A combination of stratification (on the propensity score) and linear regression has been suggested by the authors as "one of the more attractive estimators in practice" (Imbens and Wooldridge 2009, p. 41), while this estimator is also known for having performed best in an influential study by Dehejia and Wahba (1999). Such an estimator does not allow, however, for within-strata treatment effect heterogeneity. Since the Oaxaca-Blinder decomposition can be regarded as a version of flexible OLS (in the sense that it allows for gender/treatment effect heterogeneity), such a shortcoming of the estimator suggested by Imbens and Wooldridge (2009) can be addressed by a combination of stratification and the Oaxaca-Blinder decomposition.

Such a semiparametric estimator of the population average gender effect (PAGE) requires a first-step estimation of the propensity score, i.e. the conditional probability 
that a sample member is female (male) given his or her covariate values. ${ }^{14}$ The estimated propensity score is then used to divide the whole sample into $J$ strata. For each stratum $j$, a separate estimate of the population average gender effect, $\hat{\tau}_{P A G E, j}$, is obtained using the decomposition in Proposition 1. Also, the estimated variance, $\hat{V}_{P A G E, j}$, can be computed, and these estimates are averaged using a procedure in Imbens and Wooldridge (2009):

$$
\hat{\tau}_{P A G E}=\sum_{j=1}^{J}\left(\frac{N_{j 0}+N_{j 1}}{N}\right) \cdot \hat{\tau}_{P A G E, j} \text { and } \hat{V}_{P A G E}=\sum_{j=1}^{J}\left(\frac{N_{j 0}+N_{j 1}}{N}\right)^{2} \cdot \hat{V}_{P A G E, j} .
$$

Similarly, an analogous estimator of the population average gender effect on men (PAGM) involves estimating Equation 4 in each of the strata, while the population average gender effect on women (PAGW) can be estimated with the use of the Oaxaca-Blinder decomposition in Equation 5. These within-strata estimates are averaged to obtain:

$$
\begin{array}{lll}
\hat{\tau}_{P A G M}=\sum_{j=1}^{J}\left(\frac{N_{j 1}}{N_{1}}\right) \cdot \hat{\tau}_{P A G M, j} \quad & \text { and } & \hat{V}_{P A G M}=\sum_{j=1}^{J}\left(\frac{N_{j 1}}{N_{1}}\right)^{2} \cdot \hat{V}_{P A G M, j}, \\
\hat{\tau}_{P A G W}=\sum_{j=1}^{J}\left(\frac{N_{j 0}}{N_{0}}\right) \cdot \hat{\tau}_{P A G W, j} \quad & \text { and } \quad \hat{V}_{P A G W}=\sum_{j=1}^{J}\left(\frac{N_{j 0}}{N_{0}}\right)^{2} \cdot \hat{V}_{P A G W, j .} .
\end{array}
$$

These estimators require fewer functional form assumptions compared with the fully parametric approach, and such a property might be important to ensure robustness in the presence of nonlinearities in the existing wage structures (see, e.g., Barsky et al. 2002). They can also provide a useful alternative outside the gender wage differentials context, and can be used to semiparametrically estimate the PATE or the PATT. These estimators are tested in an empirical application in the next section together with parametric Oaxaca-Blinder decompositions and normalized reweighting. ${ }^{15}$

\footnotetext{
${ }^{14}$ See Frölich (2007) for an early application of methods based on the propensity score in a study of gender wage differentials.

${ }^{15}$ The latter estimator has recently been recommended by Busso, DiNardo, and McCrary (2011) on the basis of an empirical Monte Carlo study tailored to the problem of estimating black-white wage gaps.
} 


\section{An Empirical Application}

In this section various versions of the Oaxaca-Blinder decomposition are compared in an application to the UK gender wage gap. ${ }^{16}$ The source of data is the Quarterly Labour Force Survey (LFS), 2002Q1-2010Q4 (Office for National Statistics 2008-2011). In this application I append all the quarterly datasets and restrict the resulting sample in such a way that yearly representative results, for each year from 2002 to 2010, can be produced.

I further restrict the 2002-2010 LFS dataset to those individuals who are at least 18 years old, have reported nonzero average gross hourly pay, and do not have missing information on any of the control variables specified below. The outcome variable of interest is the log hourly wage and in all instances sample weights recommended for income data are used. The set of control variables includes polynomials in age, tenure, and potential experience ${ }^{17}$ as well as dummies for country of residence (4 categories), ethnic origin (11 categories), marital status (5 categories), occupation (9 categories), and public/private sector.

Table 1 presents descriptive statistics for outcome and selected control variables in all the yearly samples and Table 2 presents a comparison of various Oaxaca-Blinder estimators of the covariate-adjusted gender wage differential (including estimates of the PAGE, the PAGM, and the PAGW) as well as yearly measures of the unadjusted wage gap. All these measures have generally been falling between 2002 and 2010, and have reached their minimum values in 2010. For example, the unadjusted wage gap has fallen from 23.06 to $16.86 \log$ points, while the PAGM and the PAGW have fallen from 19.97 to $15.69 \log$ points and from 15.59 to 12.28 log points, respectively.

There are several other empirical regularities which are worth mentioning. The population average gender effect on men (PAGM) is larger than the population average gender

\footnotetext{
${ }^{16}$ All the applications of the Oaxaca-Blinder decomposition presented in this paper use the oaxaca command in Stata (Jann 2008). The new version of the Oaxaca-Blinder decomposition in Proposition 1 is also easily implementable using this command. If local macros prf and xvars contain the proportion of women in the estimation sample and the list of control variables, respectively, then this estimator can be applied as oaxaca lnwage 'xvars', by (female) weight('prf').

${ }^{17}$ For current students, potential experience is coded as 0 . For individuals with no education, potential experience is coded as the number of years since the age of fifteen.
} 
effect on women (PAGW) in a very robust way. ${ }^{18}$ This difference was as large as $3-5 \log$ points in all years and always statistically significant at the $1 \%$ level. ${ }^{19}$ In consequence, men gain typically more in comparison with similar women than women lose in comparison with similar men. As already noted, such a phenomenon means that average gender effects tend to increase with wages. Indeed, the coefficient estimates for a series of quantile regressions suggest that in most years average gender effects at the top of the UK wage distribution (90th centile) were at least 3 log points larger than at the bottom of this distribution (10th centile). ${ }^{20}$ Both time series of estimates $\left(\hat{\tau}_{P A G M}\right.$ and $\left.\hat{\tau}_{P A G W}\right)$ are also plotted in Figure 1, together with 95\% confidence intervals.

At the same time, the Reimers (1983) and Cotton (1988) estimates of the covariateadjusted gender wage differential as well as the Oaxaca-Blinder estimates of the population average gender effect (PAGE) lie always (by construction) in between the corresponding estimates of the PAGM and the PAGW. The Reimers (1983), Cotton (1988), and PAGE estimates are, however, not only bounded by $\hat{\tau}_{P A G M}$ and $\hat{\tau}_{P A G W}$, but also exactly equal (again by construction) to their weighted average, with weights equal to sample proportions of men and women (PAGE), reversed sample proportions of both groups (Cotton 1988), and 0.5 and 0.5 (Reimers 1983). Moreover, the Neumark (1988) estimates of the adjusted gender wage differential are always significantly lower (again, at the $1 \%$ level) than any other estimates (see Elder et al. 2010 for a theoretical explanation).

All of these time series of estimates, together with $\hat{\tau}_{P A G M}, \hat{\tau}_{P A G W}$, and Fortin (2008), are also plotted in Figure 2. As evident in Figure 2, the differences between $\hat{\tau}_{P A G E}$ and the Reimers (1983) and Cotton (1988) estimates are quantitatively quite small. Note, however, that this is an artifact of nearly equal sample proportions of men and women

\footnotetext{
${ }^{18}$ As noted in Section 3, such a phenomenon has already been documented in the literature without any reference to the concept of average gender effects and without a convincing explanation. See, e.g., Fortin et al. (2011, p. 47).

${ }^{19}$ All the tests of statistical significance referred to in this section are based on bootstrap standard errors of the estimated differences between the unexplained components of various versions of the OaxacaBlinder decomposition (with 100 resamples).

${ }^{20}$ One can also suspect the existence of the so-called glass ceiling effect. However, the results of the quantile regressions provide mixed evidence on the existence of a glass ceiling in the UK labor market. Although average gender effects generally increase throughout the wage distribution, their acceleration in this distribution's upper tail can rarely be regarded as "sharp". See Arulampalam et al. (2007) for related evidence on glass ceilings across EU countries, including the United Kingdom.
} 
Figure 1: A Comparison of the Population Average Gender Effect on Men (PAGM) and the Population Average Gender Effect on Women (PAGW) in the UK Labor Market

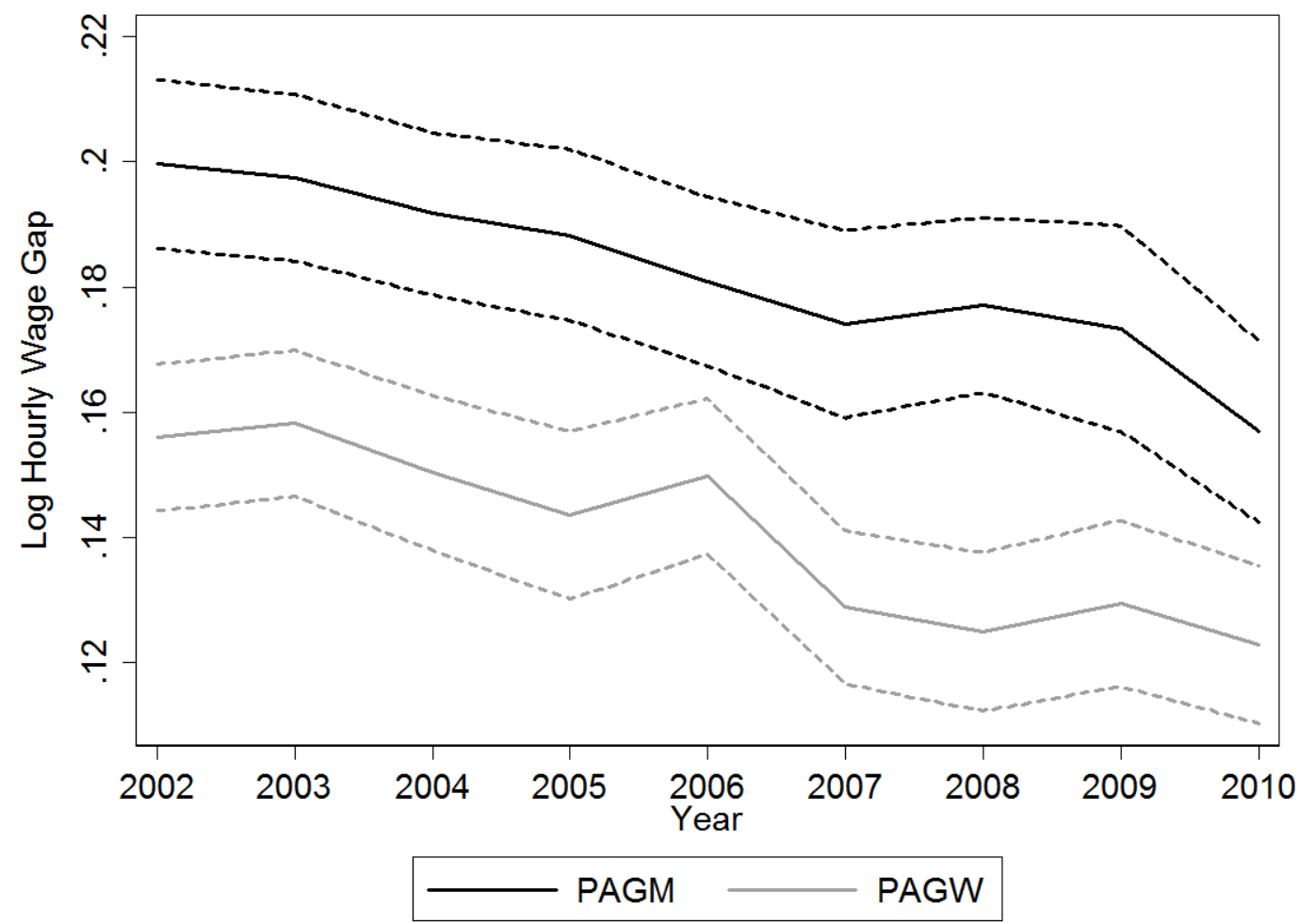

in the LFS data. If these proportions were significantly different (e.g., when analyzing ethnic/racial wage gaps, or union wage premiums, or gender wage differentials within a predominantly male/female occupation, etc.), the estimates would tend to diverge.

Also, note that these differences, however small, are always statistically significant. Further evidence on the differences between various Oaxaca-Blinder decompositions is provided in Table 3 by presenting bootstrap standard errors (based on 100 resamples) of the estimated differences between $\hat{\tau}_{P A G E}$ - the new estimator of the present paper - and other Oaxaca-Blinder estimators of the adjusted gender wage differential, and testing the statistical significance of these differences. All these differences are statistically significant at the $5 \%$ level in all years (and, in most cases, also at the $1 \%$ level). We get the expected result that $\hat{\tau}_{P A G E}$ is always significantly smaller than $\hat{\tau}_{P A G M}$ and larger than $\hat{\tau}_{P A G W}$. Also, consistent with the evidence in Elder et al. (2010), $\hat{\tau}_{P A G E}$ is always significantly larger than the unexplained component of the Neumark (1988) decomposition, and this difference is quantitatively quite large (4-6 log points). Importantly, however, Table 3 
Figure 2: A Comparison of Various Oaxaca-Blinder Estimators of the Adjusted Gender Wage Differential in the UK Labor Market

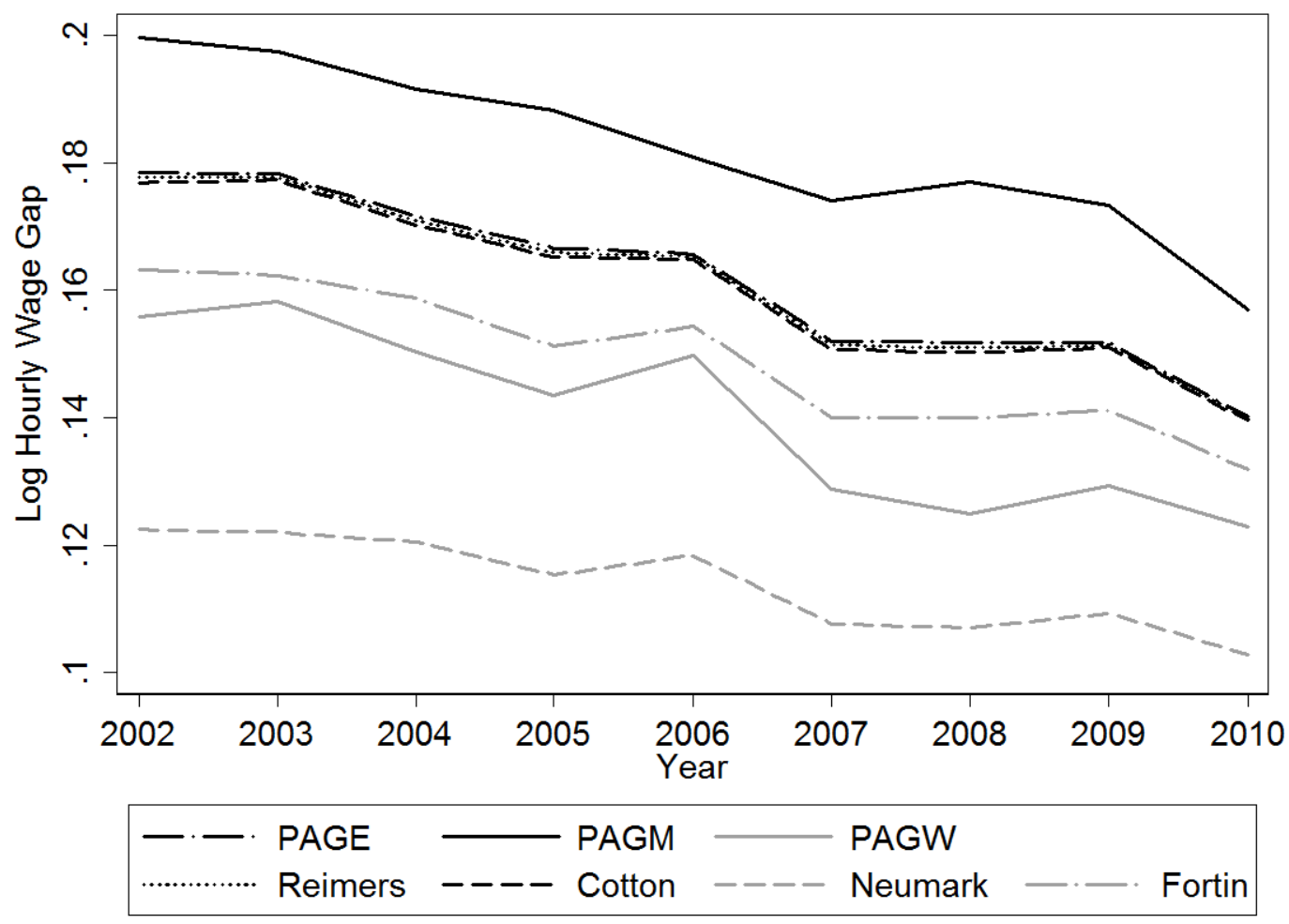

reestablishes the empirical relevance of this paper's critique of the Reimers (1983), Cotton (1988), and Fortin (2008) decompositions. In all years these estimators overstate the importance of $\hat{\tau}_{P A G W}$ (the effect on the smaller subpopulation) in estimating average gender effects, and consequently $\hat{\tau}_{P A G E}$ is always significantly larger than the unexplained components of these decompositions (because $\left.\hat{\tau}_{P A G M}>\hat{\tau}_{P A G W}\right) .{ }^{21}$ In other words, using the Reimers (1983), Cotton (1988), or Fortin (2008) decompositions would negatively bias the estimate of the population average gender effect (PAGE) in an application to

\footnotetext{
${ }^{21}$ At first, this might be seen as surprising, given the small differences between $\hat{\tau}_{P A G E}$ and selected other estimates. Take the difference between $\hat{\tau}_{P A G E}(17.86 \mathrm{log}$ points) and the Reimers (1983) estimate (17.78 log points) in 2002 as an example. Both these parameters are estimated with an error of $0.56 \log$ points, so it is natural to expect that the difference of $0.08 \log$ points between them is not statistically significant. As shown in Table 3, however, this is not the case, since this difference is actually estimated with a very small error of 0.02 . Why is the initial intuition wrong? First, note that these estimates are (by construction) positively correlated over repeated samples. When $\hat{\tau}_{P A G E}$ is relatively large, the Reimers (1983) estimate is also likely to be large, but probably smaller than $\hat{\tau}_{P A G E}\left(\right.$ since $\left.\hat{\tau}_{P A G M}>\hat{\tau}_{P A G W}\right)$. Second, note that the null hypothesis of $\frac{N_{1}}{N_{0}+N_{1}} \cdot \tau_{P A G M}+\frac{N_{0}}{N_{0}+N_{1}} \cdot \tau_{P A G W}=\frac{1}{2} \cdot \tau_{P A G M}+\frac{1}{2} \cdot \tau_{P A G W}$ can be equivalently written as $\left(\frac{N_{1}}{N_{0}+N_{1}}-\frac{1}{2}\right) \cdot\left(\tau_{P A G M}-\tau_{P A G W}\right)=0$. That the second factor $\left(\tau_{P A G M}-\tau_{P A G W}\right)$ is significantly larger than zero is evident from Figure 1. Using a one-proportion z-test and data in Table 1 , the equality of $\frac{N_{1}}{N_{0}+N_{1}}$ and $\frac{1}{2}$ can also be rejected (in favor of $\frac{N_{1}}{N_{0}+N_{1}}>\frac{1}{2}$ ). Of course, a similar logic applies also to other tests of statistical significance in Table 3.
} 
the UK labor market, although these biases can be quite small in the present application.

Tables 2-3 and Figure 2 also suggest that the empirical relationship between the Oaxaca-Blinder estimates of various average gender effects and the corresponding Fortin (2008) estimates is less clear than Proposition 5 would suggest. Indeed, while it is expected that the Fortin (2008) estimates should be approximately equal to the Cotton (1988) estimates, the former are generally significantly smaller than the latter. Nevertheless, the correlation between the differenced series is very high (0.93) and - as already noted and consistent with Proposition 5 - both the Cotton (1988) and Fortin (2008) decompositions tend to overstate the importance of the smaller group when estimating average gender effects. Indeed, also the Fortin (2008) estimates are always closer to $\hat{\tau}_{P A G W}$ (the effect on the smaller group) than $\hat{\tau}_{P A G M}$ (the effect on the larger group), while such a property is clearly undesirable.

As a robustness check, Table 4 presents a comparison of various estimators of the PAGE, the PAGM, and the PAGW, both parametric (Oaxaca-Blinder) and semiparametric (stratification and Oaxaca-Blinder, normalized reweighting). Importantly, all the qualitative results on the relationship between the PAGM and the PAGW are confirmed. Also, the trends in the estimated average gender effects are very similar. This pattern is consistent with the recent evidence in Nopo (2008) who has concluded that the linearity assumption is not particularly problematic when decomposing gender wage gaps.

\section{Summary}

In this paper I have introduced a new concept of average gender effects, and have shown how this concept can be used to reformulate the Oaxaca-Blinder approach to decomposing gender wage differentials. I have argued for a framework in which current wages of men are compared with current wages of similar women (and vice versa), and not with an hypothesized "nondiscriminatory" wage structure. To provide a tool for such comparisons, I have derived an alternative solution to the comparison group choice problem which is fundamental in Oaxaca-Blinder, while this new decomposition can be used to 
consistently estimate the population average gender effect (PAGE) and the population average treatment effect (PATE). I have also pointed out that several other versions of the Oaxaca-Blinder decomposition (Reimers 1983; Cotton 1988; Fortin 2008) can produce misleading results in empirical applications, since each of them is likely to overstate the importance of the smaller of the subpopulations (men and women, treated and nontreated, union and nonunion workers, etc.) when estimating average gender (treatment) effects.

This approach has also been illustrated empirically in an application to UK gender wage differentials. Using data from the Quarterly Labour Force Survey (LFS) I have estimated the population average gender effect (PAGE), the population average gender effect on men (PAGM), and the population average gender effect on women (PAGW) for the UK working population, for each year from 2002 to 2010. The major empirical finding of this study is that men gain typically more in comparison with similar women than women lose in comparison with similar men (the PAGM is consistently larger than the PAGW). This phenomenon is explained by the fact that average gender effects tend to increase with wages and this is indeed the case in the UK labor market.

Future work might involve establishing formal conditions under which causal effects of gender can be estimated (for seminal discussions, see Greiner and Rubin 2011 and Huber 2012) and, as already suggested by Fortin et al. (2011), improving the economic structure behind decomposition methods. Before these paths can be successfully taken, however, it is crucial to bridge the gap between the decomposition literature and the treatment effects literature. Following an important review in Fortin et al. (2011), the present paper has attempted to take this ongoing discussion one step further by providing a new (Oaxaca-Blinder) estimator of the PATE as well as clarifying the treatment-effects interpretation of the Reimers (1983), Cotton (1988), and Fortin (2008) decompositions. 


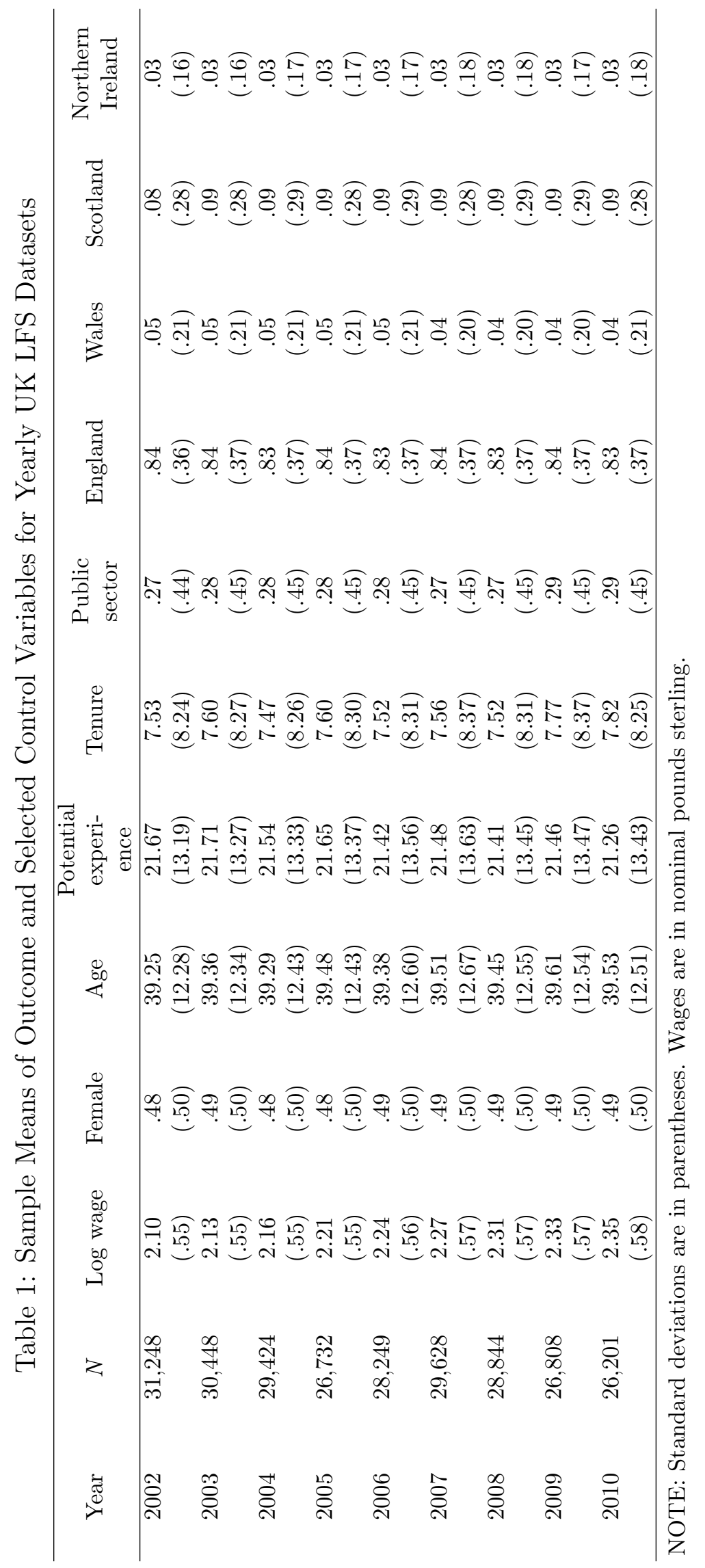




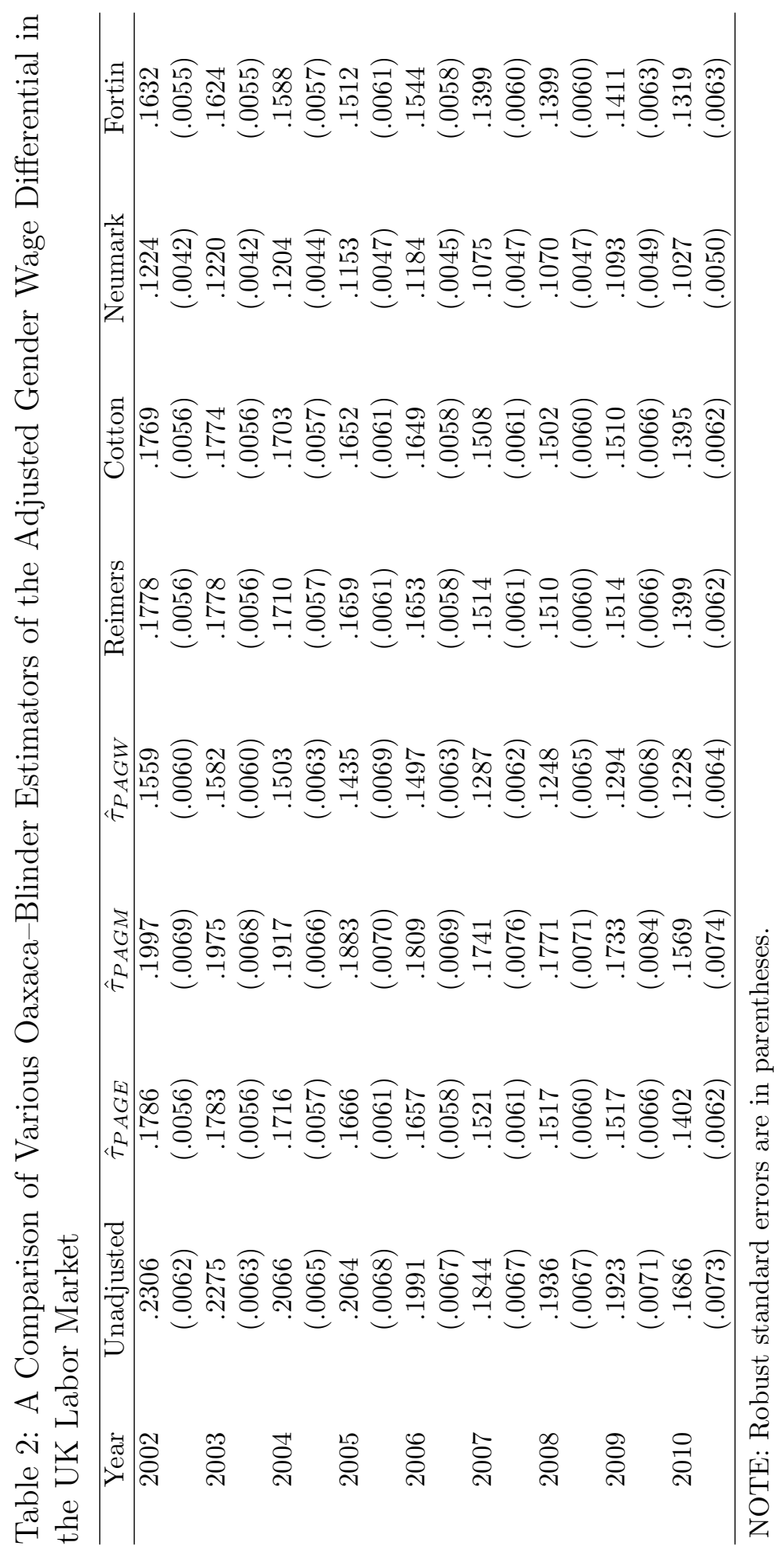




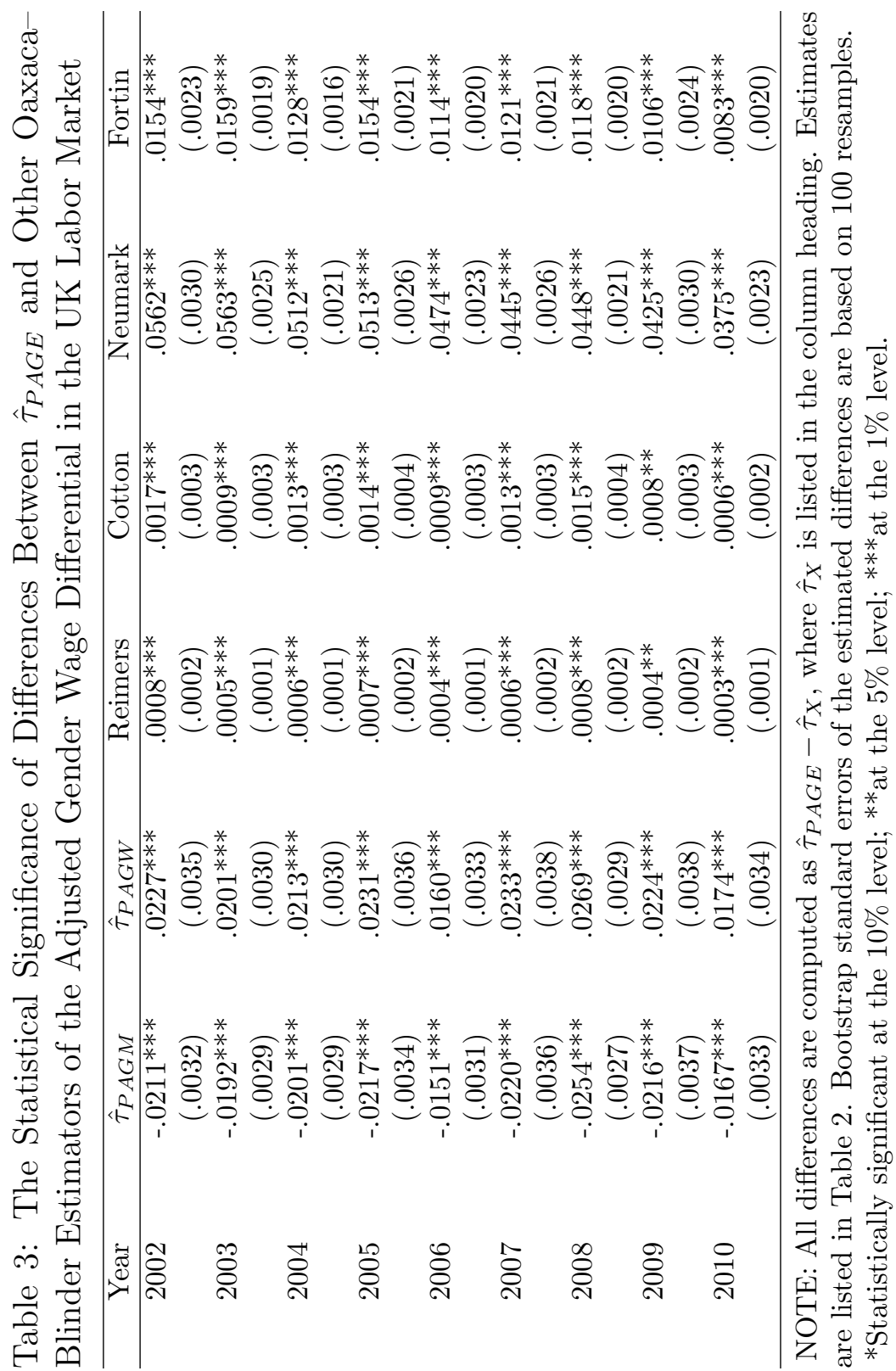




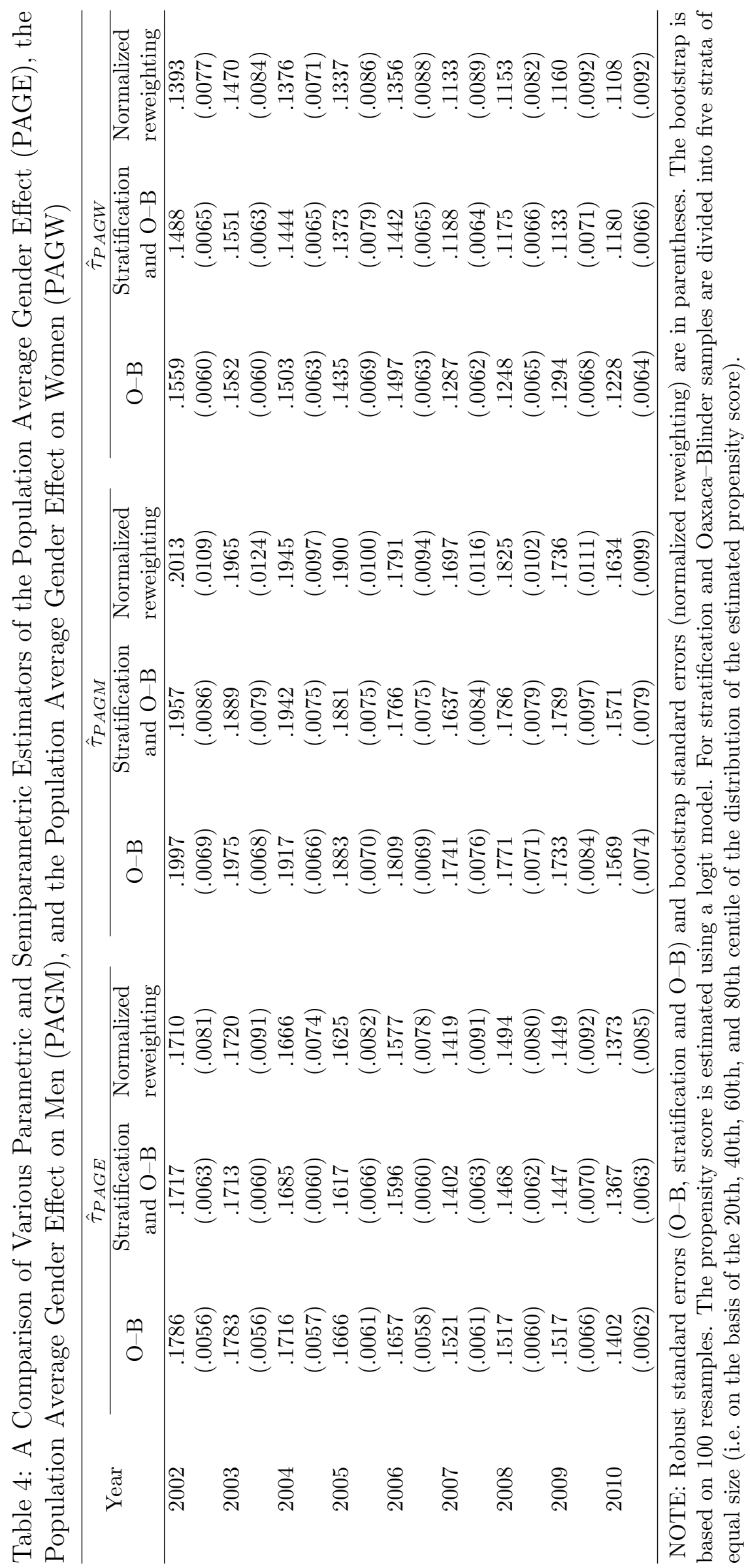




\section{Appendix}

Proof of Proposition 3. (Note that this proof is due to Słoczyński 2012.) Combine Equation 7 with $\beta^{*}=\frac{N_{1}}{N_{0}+N_{1}} \cdot \beta_{1}+\frac{N_{0}}{N_{0}+N_{1}} \cdot \beta_{0}$ and reformulate:

$$
\begin{aligned}
\mathrm{E}\left[y_{i} \mid d_{i}=1\right]-\mathrm{E}\left[y_{i} \mid d_{i}=0\right]= & \mathrm{E}\left[X_{i} \mid d_{i}=1\right] \cdot\left(\beta_{1}-\beta^{*}\right)+\mathrm{E}\left[X_{i} \mid d_{i}=0\right] \cdot\left(\beta^{*}-\beta_{0}\right) \\
& +\left(\mathrm{E}\left[X_{i} \mid d_{i}=1\right]-\mathrm{E}\left[X_{i} \mid d_{i}=0\right]\right) \cdot \beta^{*} \\
= & \mathrm{E}\left[X_{i} \mid d_{i}=1\right] \cdot\left(\beta_{1}-\left(\frac{N_{1}}{N_{0}+N_{1}} \cdot \beta_{1}+\frac{N_{0}}{N_{0}+N_{1}} \cdot \beta_{0}\right)\right) \\
& +\mathrm{E}\left[X_{i} \mid d_{i}=0\right] \cdot\left(\left(\frac{N_{1}}{N_{0}+N_{1}} \cdot \beta_{1}+\frac{N_{0}}{N_{0}+N_{1}} \cdot \beta_{0}\right)-\beta_{0}\right) \\
& +\left(\mathrm{E}\left[X_{i} \mid d_{i}=1\right]-\mathrm{E}\left[X_{i} \mid d_{i}=0\right]\right) \cdot \beta^{*} \\
= & \frac{N_{0}}{N_{0}+N_{1}} \cdot \mathrm{E}\left[X_{i} \mid d_{i}=1\right] \cdot\left(\beta_{1}-\beta_{0}\right) \\
& +\frac{N_{1}}{N_{0}+N_{1}} \cdot \mathrm{E}\left[X_{i} \mid d_{i}=0\right] \cdot\left(\beta_{1}-\beta_{0}\right) \\
& +\left(\mathrm{E}\left[X_{i} \mid d_{i}=1\right]-\mathrm{E}\left[X_{i} \mid d_{i}=0\right]\right) \cdot \beta^{*} \\
= & \frac{N_{0}}{N_{0}+N_{1}} \cdot \tau_{P A T T}+\frac{N_{1}}{N_{0}+N_{1}} \cdot \tau_{P A T N} \\
& +\left(\mathrm{E}\left[X_{i} \mid d_{i}=1\right]-\mathrm{E}\left[X_{i} \mid d_{i}=0\right]\right) \cdot \beta^{*} .
\end{aligned}
$$

Q.E.D.

Proof of Proposition 4. (Note that this proof is due to Wooldridge 2002.) Decompose both potential outcomes into their population means and individual-specific stochastic components:

$$
y_{0 i}=\mathrm{E}\left[y_{0 i}\right]+\epsilon_{0 i} \quad \text { and } \quad y_{1 i}=\mathrm{E}\left[y_{1 i}\right]+\epsilon_{1 i}
$$

where $\mathrm{E}\left[\epsilon_{0 i}\right]=\mathrm{E}\left[\epsilon_{1 i}\right]=0$. Note that the assumption of treatment effect homogeneity is equivalent to $\mathrm{E}\left[\epsilon_{0 i} \mid X_{i}\right]=\mathrm{E}\left[\epsilon_{1 i} \mid X_{i}\right]$, i.e. there are no individual-specific gains from participation (treatment effects). To see this, combine this assumption with conditional 
mean independence:

$$
\begin{aligned}
\mathrm{E}\left[y_{1 i} \mid X_{i}, d_{i}\right]-\mathrm{E}\left[y_{0 i} \mid X_{i}, d_{i}\right] & =\mathrm{E}\left[y_{1 i} \mid X_{i}\right]-\mathrm{E}\left[y_{0 i} \mid X_{i}\right] \\
& =\mathrm{E}\left[y_{1 i}-y_{0 i}\right]+\mathrm{E}\left[\epsilon_{1 i}-\epsilon_{0 i} \mid X_{i}\right] \\
& =\mathrm{E}\left[y_{1 i}-y_{0 i}\right] \\
& =\tau_{P A T E} .
\end{aligned}
$$

Since $\mathrm{E}\left[y_{1 i} \mid X_{i}, d_{i}\right]-\mathrm{E}\left[y_{0 i} \mid X_{i}, d_{i}\right]=\tau_{P A T E}$, we also have $\mathrm{E}\left[y_{1 i} \mid d_{i}\right]-\mathrm{E}\left[y_{0 i} \mid d_{i}\right]=\tau_{P A T E}$ by the law of iterated expectations, and therefore $\tau_{P A T E}=\tau_{P A T T}=\tau_{P A T N}$. Next, we can write $y_{i}$ as:

$$
\begin{aligned}
y_{i} & =y_{1 i} \cdot d_{i}+y_{0 i} \cdot\left(1-d_{i}\right) \\
& =y_{0 i}+d_{i} \cdot\left(y_{1 i}-y_{0 i}\right) \\
& =\mathrm{E}\left[y_{0 i}\right]+\epsilon_{0 i}+d_{i} \cdot\left(\mathrm{E}\left[y_{1 i}\right]+\epsilon_{1 i}-\mathrm{E}\left[y_{0 i}\right]-\epsilon_{0 i}\right) \\
& =\mathrm{E}\left[y_{0 i}\right]+d_{i} \cdot \tau_{P A T E}+\epsilon_{0 i}+d_{i} \cdot\left(\epsilon_{1 i}-\epsilon_{0 i}\right),
\end{aligned}
$$

and therefore:

$$
\begin{aligned}
\mathrm{E}\left[y_{i} \mid X_{i}, d_{i}\right] & =\mathrm{E}\left[y_{0 i}\right]+d_{i} \cdot \tau_{P A T E}+\mathrm{E}\left[\epsilon_{0 i} \mid X_{i}, d_{i}\right]+d_{i} \cdot \mathrm{E}\left[\epsilon_{1 i}-\epsilon_{0 i} \mid X_{i}, d_{i}\right] \\
& =\mathrm{E}\left[y_{0 i}\right]+d_{i} \cdot \tau_{P A T E}+\mathrm{E}\left[\epsilon_{0 i} \mid X_{i}\right]+d_{i} \cdot \mathrm{E}\left[\epsilon_{1 i}-\epsilon_{0 i} \mid X_{i}\right] \\
& =\mathrm{E}\left[y_{0 i}\right]+d_{i} \cdot \tau_{P A T E}+\mathrm{E}\left[\epsilon_{0 i} \mid X_{i}\right] \\
& =\alpha+d_{i} \cdot \tau_{P A T E}+g\left(X_{i}\right) \cdot \beta
\end{aligned}
$$

where $\mathrm{E}\left[\epsilon_{0 i} \mid X_{i}\right]=\eta+g\left(X_{i}\right) \cdot \beta$ and $\alpha=\eta+\mathrm{E}\left[y_{0 i}\right]$. Therefore, $\tau_{P A T E}, \tau_{P A T T}$, and $\tau_{P A T N}$ can be estimated by ordinary least squares as the coefficient on $d_{i}$ in the regression of $y_{i}$ on $1, d_{i}$, and $g\left(X_{i}\right)$.

Q.E.D. 
Proof of Proposition 5. (Note that this proof is due to Elder et al. 2010 and Słoczyński 2012.) In a recent paper, Elder et al. (2010) have proven that the coefficient on a binary variable in linear least squares regression is equal (by construction) to the unexplained component of the Cotton (1988) decomposition, provided that $X_{i}$ is a scalar whose variance is equal in both subpopulations of interest. This result has recently been accompanied by a lemma (Proposition 3) on the Cotton (1988) decomposition and treatment effects (Słoczyński 2012). Together these results imply Proposition 5. Below, I restate a simplified version of the proof in Elder et al. (2010). See also Słoczyński (2012).

Using $x_{i}$ to denote the scalar covariate, the true data generating process can be specified as (note that this process allows for treatment effect heterogeneity):

$$
y_{i}=\lambda_{0}+\lambda_{d} d_{i}+\lambda_{x} x_{i}+\lambda_{d x} d_{i} x_{i}+\epsilon_{i},
$$

where also:

$$
\mathrm{V}\left[x_{i} \mid d_{i}=1\right]=\mathrm{V}\left[x_{i} \mid d_{i}=0\right]=\sigma_{d}^{2} .
$$

Under this model, and also combining Equation 7 with $\beta^{*}=\frac{N_{1}}{N_{0}+N_{1}} \cdot \beta_{1}+\frac{N_{0}}{N_{0}+N_{1}} \cdot \beta_{0}$, the unexplained component of the Cotton (1988) decomposition can be written as:

$$
\begin{aligned}
\tau_{C}= & \left(\mathrm{E}\left[y_{i} \mid d_{i}=1\right]-\mathrm{E}\left[y_{i} \mid d_{i}=0\right]\right)-\left(\mathrm{E}\left[X_{i} \mid d_{i}=1\right]-\mathrm{E}\left[X_{i} \mid d_{i}=0\right]\right) \cdot \beta^{*} \\
= & \frac{\operatorname{Cov}\left[d_{i}, y_{i}\right]}{\mathrm{V}\left[d_{i}\right]}-\frac{\operatorname{Cov}\left[d_{i}, x_{i}\right]}{\mathrm{V}\left[d_{i}\right]} \\
& \cdot\left(\frac{N_{1}}{N_{0}+N_{1}} \cdot \frac{\operatorname{Cov}\left[x_{i}, y_{i} \mid d_{i}=1\right]}{\mathrm{V}\left[x_{i} \mid d_{i}=1\right]}+\frac{N_{0}}{N_{0}+N_{1}} \cdot \frac{\operatorname{Cov}\left[x_{i}, y_{i} \mid d_{i}=0\right]}{\mathrm{V}\left[x_{i} \mid d_{i}=0\right]}\right) \\
= & \frac{\operatorname{Cov}\left[d_{i}, y_{i}\right]}{\mathrm{V}\left[d_{i}\right]}-\frac{\operatorname{Cov}\left[d_{i}, x_{i}\right]}{\mathrm{V}\left[d_{i}\right]} \\
& \cdot \frac{\frac{N_{1}}{N_{0}+N_{1}} \cdot \operatorname{Cov}\left[x_{i}, y_{i} \mid d_{i}=1\right]+\frac{N_{0}}{N_{0}+N_{1}} \cdot \operatorname{Cov}\left[x_{i}, y_{i} \mid d_{i}=0\right]}{\sigma_{d}^{2}} .
\end{aligned}
$$

The incorrectly specified model (which assumes treatment effect homogeneity) can be written as:

$$
y_{i}=\alpha+\beta_{d} d_{i}+\beta_{x} x_{i}+v_{i} .
$$


We therefore need to prove that $\beta_{d}=\tau_{C}$. Using $\tilde{d}_{i}$ to denote the residual from a regression of $d_{i}$ on $x_{i}$, we can write:

$$
\begin{aligned}
& \beta_{d}=\frac{\operatorname{Cov}\left[\tilde{d}_{i}, y_{i}\right]}{\mathrm{V}\left[\tilde{d}_{i}\right]} \\
& =\frac{\operatorname{Cov}\left[d_{i}-x_{i} \cdot \operatorname{Cov}\left[d_{i}, x_{i}\right] / \mathrm{V}\left[x_{i}\right], y_{i}\right]}{\operatorname{V}\left[\tilde{d}_{i}\right]} \\
& =\frac{\operatorname{Cov}\left[d_{i}, y_{i}\right]}{\mathrm{V}\left[\tilde{d}_{i}\right]}-\frac{\operatorname{Cov}\left[d_{i}, x_{i}\right]}{\mathrm{V}\left[x_{i}\right]} \cdot \frac{\operatorname{Cov}\left[x_{i}, y_{i}\right]}{\mathrm{V}\left[\tilde{d}_{i}\right]} \\
& =\frac{1}{\mathrm{~V}\left[\tilde{d}_{i}\right]} \cdot\left(\operatorname{Cov}\left[d_{i}, y_{i}\right]-\frac{\operatorname{Cov}\left[d_{i}, x_{i}\right] \cdot \operatorname{Cov}\left[x_{i}, y_{i}\right]}{\mathrm{V}\left[x_{i}\right]}\right) \\
& =\frac{\mathrm{V}\left[x_{i}\right]}{\mathrm{V}\left[d_{i}\right] \cdot \mathrm{V}\left[x_{i}\right]-\operatorname{Cov}\left[d_{i}, x_{i}\right]^{2}} \cdot\left(\operatorname{Cov}\left[d_{i}, y_{i}\right]-\frac{\operatorname{Cov}\left[d_{i}, x_{i}\right] \cdot \operatorname{Cov}\left[x_{i}, y_{i}\right]}{\mathrm{V}\left[x_{i}\right]}\right) \\
& =\frac{\operatorname{Cov}\left[d_{i}, y_{i}\right] \cdot \mathrm{V}\left[x_{i}\right]-\operatorname{Cov}\left[d_{i}, x_{i}\right] \cdot \operatorname{Cov}\left[x_{i}, y_{i}\right]}{\mathrm{V}\left[d_{i}\right] \cdot \mathrm{V}\left[x_{i}\right]-\operatorname{Cov}\left[d_{i}, x_{i}\right]^{2}} \\
& =\frac{\operatorname{Cov}\left[d_{i}, y_{i}\right] \cdot \mathrm{V}\left[x_{i}\right]-\operatorname{Cov}\left[d_{i}, x_{i}\right]^{2} \cdot \operatorname{Cov}\left[d_{i}, y_{i}\right] / \mathrm{V}\left[d_{i}\right]}{\mathrm{V}\left[d_{i}\right] \cdot \mathrm{V}\left[x_{i}\right]-\operatorname{Cov}\left[d_{i}, x_{i}\right]^{2}} \\
& -\frac{\operatorname{Cov}\left[d_{i}, x_{i}\right] \cdot \operatorname{Cov}\left[x_{i}, y_{i}\right]-\operatorname{Cov}\left[d_{i}, x_{i}\right]^{2} \cdot \operatorname{Cov}\left[d_{i}, y_{i}\right] / \mathrm{V}\left[d_{i}\right]}{\mathrm{V}\left[d_{i}\right] \cdot \mathrm{V}\left[x_{i}\right]-\operatorname{Cov}\left[d_{i}, x_{i}\right]^{2}} \\
& =\frac{\operatorname{Cov}\left[d_{i}, y_{i}\right]}{\mathrm{V}\left[d_{i}\right]}-\frac{\operatorname{Cov}\left[d_{i}, x_{i}\right]}{\mathrm{V}\left[d_{i}\right]} \cdot \frac{\operatorname{Cov}\left[x_{i}, y_{i}\right] \cdot \mathrm{V}\left[d_{i}\right]-\operatorname{Cov}\left[d_{i}, x_{i}\right] \cdot \operatorname{Cov}\left[d_{i}, y_{i}\right]}{\mathrm{V}\left[d_{i}\right] \cdot \mathrm{V}\left[x_{i}\right]-\operatorname{Cov}\left[d_{i}, x_{i}\right]^{2}} \\
& =\frac{\operatorname{Cov}\left[d_{i}, y_{i}\right]}{\mathrm{V}\left[d_{i}\right]}-\frac{\operatorname{Cov}\left[d_{i}, x_{i}\right]}{\mathrm{V}\left[d_{i}\right]} \cdot \frac{\operatorname{Cov}\left[x_{i}, y_{i}\right]-\operatorname{Cov}\left[d_{i}, x_{i}\right] \cdot \operatorname{Cov}\left[d_{i}, y_{i}\right] / \mathrm{V}\left[d_{i}\right]}{\mathrm{V}\left[x_{i}\right]-\operatorname{Cov}\left[d_{i}, x_{i}\right]^{2} / \mathrm{V}\left[d_{i}\right]} \\
& =\frac{\operatorname{Cov}\left[d_{i}, y_{i}\right]}{\mathrm{V}\left[d_{i}\right]}-\frac{\operatorname{Cov}\left[d_{i}, x_{i}\right]}{\mathrm{V}\left[d_{i}\right]} \\
& \cdot \frac{\frac{N_{1}}{N_{0}+N_{1}} \cdot \operatorname{Cov}\left[x_{i}, y_{i} \mid d_{i}=1\right]+\frac{N_{0}}{N_{0}+N_{1}} \cdot \operatorname{Cov}\left[x_{i}, y_{i} \mid d_{i}=0\right]}{\sigma_{d}^{2}} \\
& =\tau_{C},
\end{aligned}
$$

where the next to the last equality follows from the decomposition of (co)variance (see Słoczyński 2012 for details).

Q.E.D. 


\section{References}

Albrecht, James, Anders Björklund, and Susan Vroman. 2003. Is there a glass ceiling in Sweden? Journal of Labor Economics 21:145-77.

Altonji, Joseph G., and Charles R. Pierret. 2001. Employer learning and statistical discrimination. Quarterly Journal of Economics 116:313-50.

Angrist, Joshua D., and Jörn-Steffen Pischke. 2009. Mostly harmless econometrics: An empiricist's companion. Princeton and Oxford: Princeton University Press.

Antonovics, Kate, Peter Arcidiacono, and Randall Walsh. 2005. Games and discrimination: Lessons from "The Weakest Link". Journal of Human Resources 40:918-47.

Arulampalam, Wiji, Alison L. Booth, and Mark L. Bryan. 2007. Is there a glass ceiling over Europe? Exploring the gender pay gap across the wage distribution. Industrial and Labor Relations Review 60:163-86.

Ayres, Ian, and Peter Siegelman. 1995. Race and gender discrimination in bargaining for a new car. American Economic Review 85:304-21.

Barsky, Robert, John Bound, Kerwin Kofi Charles, and Joseph P. Lupton. 2002. Accounting for the black-white wealth gap: A nonparametric approach. Journal of the American Statistical Association 97:663-73.

Belley, Philippe, Nathalie Havet, and Guy Lacroix. 2012. Wage growth and job mobility in the early career: Testing a statistical discrimination model of the gender wage gap. IZA Discussion Paper no. 6893, Institute for the Study of Labor, Bonn.

Black, Dan, Amelia Haviland, Seth Sanders, and Lowell Taylor. 2006. Why do minority men earn less? A study of wage differentials among the highly educated. Review of Economics and Statistics 88:300-13.

Black, Dan A., Amelia M. Haviland, Seth G. Sanders, and Lowell J. Taylor. 2008. Gender wage disparities among the highly educated. Journal of Human Resources 43:630-59.

Blackburn, McKinley L. 2004. The role of test scores in explaining race and gender differences in wages. Economics of Education Review 23:555-76.

Blinder, Alan S. 1973. Wage discrimination: Reduced form and structural estimates. Journal of Human Resources 8:436-55. 
Blundell, Richard, and Monica Costa Dias. 2009. Alternative approaches to evaluation in empirical microeconomics. Journal of Human Resources 44:565-640.

Brown, Charles, and Mary Corcoran. 1997. Sex-based differences in school content and the male-female wage gap. Journal of Labor Economics 15:431-65.

Busso, Matias, John DiNardo, and Justin McCrary. 2011. New evidence on the finite sample properties of propensity score reweighting and matching estimators. Unpublished manuscript, School of Law, University of California, Berkeley.

Chernozhukov, Victor, Iván Fernández-Val, and Blaise Melly. 2012. Inference on counterfactual distributions. Econometrica (forthcoming).

Cotton, Jeremiah. 1988. On the decomposition of wage differentials. Review of Economics and Statistics 70:236-43.

de la Rica, Sara, Juan J. Dolado, and Vanesa Llorens. 2008. Ceilings or floors? Gender wage gaps by education in Spain. Journal of Population Economics 21:751-76.

Dehejia, Rajeev H., and Sadek Wahba. 1999. Causal effects in nonexperimental studies: Reevaluating the evaluation of training programs. Journal of the American Statistical Association 94:1053-62.

DiNardo, John, Nicole M. Fortin, and Thomas Lemieux. 1996. Labor market institutions and the distribution of wages, 1973-1992: A semiparametric approach. Econometrica 64:1001-44

Duncan, Gregory M., and Duane E. Leigh. 1985. The endogeneity of union status: An empirical test. Journal of Labor Economics 3:385-402.

Elder, Todd E., John H. Goddeeris, and Steven J. Haider. 2010. Unexplained gaps and Oaxaca-Blinder decompositions. Labour Economics 17:284-90.

Firpo, Sergio, Nicole Fortin, and Thomas Lemieux. 2007. Decomposing wage distributions using recentered influence function regressions. Unpublished manuscript, Department of Economics, University of British Columbia.

Fortin, Nicole M. 2005. Gender role attitudes and the labour-market outcomes of women across OECD countries. Oxford Review of Economic Policy 21:416-38.

Fortin, Nicole M. 2008. The gender wage gap among young adults in the United States: 
The importance of money versus people. Journal of Human Resources 43:884-918.

Fortin, Nicole, Thomas Lemieux, and Sergio Firpo. 2011. Decomposition methods in economics. In Handbook of labor economics, vol. 4A, ed. Orley Ashenfelter and David Card. San Diego and Amsterdam: Elsevier.

Frölich, Markus. 2007. Propensity score matching without conditional independence assumption - with an application to the gender wage gap in the United Kingdom. Econometrics Journal 10:359-407.

Greiner, D. James, and Donald B. Rubin. 2011. Causal effects of perceived immutable characteristics. Review of Economics and Statistics 93:775-85.

Huber, Martin. 2012. Causal pitfalls in the decomposition of wage gaps. Unpublished manuscript, University of St. Gallen.

Ichino, Andrea, and Enrico Moretti. 2009. Biological gender differences, absenteeism, and the earnings gap. American Economic Journal: Applied Economics 1:183-218.

Imbens, Guido W., and Jeffrey M. Wooldridge. 2009. Recent developments in the econometrics of program evaluation. Journal of Economic Literature 47:5-86.

Jann, Ben. 2008. The Blinder-Oaxaca decomposition for linear regression models. Stata Journal 8:453-79.

Juhn, Chinhui, Kevin M. Murphy, and Brooks Pierce. 1993. Wage inequality and the rise in returns to skill. Journal of Political Economy 101:410-42.

Kline, Patrick. 2011. Oaxaca-Blinder as a reweighting estimator. American Economic Review: Papers 83 Proceedings 101:532-37.

Leibbrandt, Andreas, and John A. List. 2012. Do women avoid salary negotiations? Evidence from a large scale natural field experiment. NBER Working Paper no. 18511, National Bureau of Economic Research, Cambridge.

Levitt, Steven D. 2004. Testing theories of discrimination: Evidence from "Weakest Link". Journal of Law and Economics 47:431-52.

Lewis, H. Gregg. 1986. Union relative wage effects: A survey. Chicago and London: University of Chicago Press.

List, John A. 2004. The nature and extent of discrimination in the marketplace: Evidence 
from the field. Quarterly Journal of Economics 119:49-89.

Loury, Linda Datcher. 1997. The gender earnings gap among college-educated workers. Industrial and Labor Relations Review 50:580-93.

Machado, José A. F., and José Mata. 2005. Counterfactual decomposition of changes in wage distributions using quantile regression. Journal of Applied Econometrics 20:445-65.

Machin, Stephen, and Patrick A. Puhani. 2003. Subject of degree and the gender wage differential: Evidence from the UK and Germany. Economics Letters 79:393-400.

Manning, Alan, and Joanna Swaffield. 2008. The gender gap in early-career wage growth. Economic Journal 118:983-1024.

Melly, Blaise. 2005. Decomposition of differences in distribution using quantile regression. Labour Economics 12:577-90.

Melly, Blaise. 2006. Applied quantile regression. PhD diss., University of St. Gallen.

Mora, Ricardo. 2008. A nonparametric decomposition of the Mexican American average wage gap. Journal of Applied Econometrics 23:463-85.

Mueller, Gerrit, and Erik Plug. 2006. Estimating the effect of personality on male and female earnings. Industrial and Labor Relations Review 60:3-22.

Neumark, David. 1988. Employers' discriminatory behavior and the estimation of wage discrimination. Journal of Human Resources 23:279-95.

Neumark, David. 1999. Wage differentials by race and sex: The roles of taste discrimination and labor market information. Industrial Relations 38:414-45.

Ñopo, Hugo. 2008. Matching as a tool to decompose wage gaps. Review of Economics and Statistics 90:290-99.

Oaxaca, Ronald. 1973. Male-female wage differentials in urban labor markets. International Economic Review 14:693-709.

Oaxaca, Ronald L., and Michael R. Ransom. 1988. Searching for the effect of unionism on the wages of union and nonunion workers. Journal of Labor Research 9:139-48.

Oaxaca, Ronald L., and Michael R. Ransom. 1994. On discrimination and the decomposition of wage differentials. Journal of Econometrics 61:5-21.

Oaxaca, Ronald L., and Michael R. Ransom. 1999. Identification in detailed wage decom- 
positions. Review of Economics and Statistics 81:154-57.

Oettinger, Gerald S. 1996. Statistical discrimination and the early career evolution of the black-white wage gap. Journal of Labor Economics 14:52-78.

Office for National Statistics, Social and Vital Statistics Division and Northern Ireland Statistics and Research Agency, Central Survey Unit. Various years. Quarterly labour force survey. Colchester, Essex: UK Data Archive.

Office for National Statistics, Social Survey Division and Northern Ireland Statistics and Research Agency, Central Survey Unit. Various years. Quarterly labour force survey. Colchester, Essex: UK Data Archive.

Reimers, Cordelia W. 1983. Labor market discrimination against Hispanic and black men. Review of Economics and Statistics 65:570-79.

Robins, James M., Andrea Rotnitzky, and Lue Ping Zhao. 1994. Estimation of regression coefficients when some regressors are not always observed. Journal of the American Statistical Association 89:846-66.

Siniver, Erez. 2011. Testing for statistical discrimination: The case of immigrant physicians in Israel. Labour 25:155-66.

Słoczyński, Tymon. 2012. New evidence on linear regression and treatment effect heterogeneity. MPRA Paper no. 39524, Munich Personal RePEc Archive.

Weichselbaumer, Doris, and Rudolf Winter-Ebmer. 2005. A meta-analysis of the international gender wage gap. Journal of Economic Surveys 19:479-511.

Wooldridge, Jeffrey M. 2002. Econometric analysis of cross section and panel data. Cambridge and London: MIT Press. 